This item was submitted to Loughborough's Research Repository by the author.

Items in Figshare are protected by copyright, with all rights reserved, unless otherwise indicated.

\title{
Liquidity spillovers in sovereign bond and CDS markets: an analysis of the Eurozone sovereign debt crisis
}

PLEASE CITE THE PUBLISHED VERSION

http://dx.doi.org/10.1016/j.jebo.2011.10.013

PUBLISHER

(C) Elsevier

VERSION

SMUR (Submitted Manuscript Under Review)

\section{PUBLISHER STATEMENT}

This work is made available according to the conditions of the Creative Commons Attribution-NonCommercialNoDerivatives 4.0 International (CC BY-NC-ND 4.0) licence. Full details of this licence are available at: https://creativecommons.org/licenses/by-nc-nd/4.0/

\section{LICENCE}

CC BY-NC-ND 4.0

\section{REPOSITORY RECORD}

Calice, Giovanni, Jing Chen, and Julian M. Williams. 2019. "Liquidity Spillovers in Sovereign Bond and CDS Markets: An Analysis of the Eurozone Sovereign Debt Crisis". figshare. https://hdl.handle.net/2134/24212. 


\title{
Liquidity Spillovers in Sovereign Bond and CDS Markets:
}

\author{
An Analysis of The Eurozone Sovereign Debt Crisis
}

Giovanni Calice, Jing Chen, Julian Williams*

\begin{abstract}
At the end of 2009, countries in the Eurozone (euro area) began to experience a sudden divergence of bond yields as the market perception of sovereign default risk increased. The theory of complete markets suggests that sovereign debt and credit default swap (CDS) credit spreads should track each other closely. In addition, liquidity risk should be priced into both instruments in such a way that buying exposure to the same default risk is identically priced. We use a time-varying vector autoregression framework to establish the credit and liquidity spreads interactions over the 2009-2010 crisis period. We find substantial variation in the patterns of the transmission effect between maturities and across countries. Our major result is that for several countries, including Greece, Ireland and Portugal the liquidity of the sovereign CDS market has a substantial time varying influence on sovereign bond credit spreads. This evidence is of particular importance in the current policy context.
\end{abstract}

Keywords: Credit Default Swaps, Liquidity, Sovereign Bonds, Credit Spreads JEL Classification: G11, G12, G14

\section{Introduction}

This paper develops an empirical model of the co-evolution of credit and liquidity spreads in soveriegn bond and CDS markets. We apply this model to study the liquidity and credit interactions for Eurozone countries over the January 1, 2007 to October 1, 2010 period.

During November 2009, shortly after the election of a new Greek government, the Greek public sector deficit was revised from $6 \%$ to $12.7 \%$ of GDP. This event initiated a sovereign debt crisis that has resulted in large financial interventions in Greece, Ireland and Portugal. The resultant fluctuations in financial markets and sudden impact on fiscal policy in the affected states is often referred to as the 'Eurozone sovereign debt crisis'.

The deterioration in government finances, after the credit crisis of 2008, led to a sudden loss of confidence in sovereign debt markets, which revealed itself in the form of widening credit spreads between several euro area members and the Eurozone's largest economy, Germany. The response by Eurozone member states

\footnotetext{
* Corresponding Author. This paper was partly prepared while Giovanni Calice stayed at the European Commission under the DG ECFIN Visiting Fellows Programme in December 2010 and January 2011. We are grateful to the Commission for valuable research support. This is an updated version of the working paper entitled: "Liquidity Interactions in Credit Markets: A preliminary Analysis of the Eurozone Sovereign Debt Crisis", presented in support of written evidence to the United Kingdom House of Lords select committee on Credit Default Swaps and Short Selling, January 25, 2011, full text: http: //www.parliament.uk/documents/lords-committees/eu-sub-com-a/CDSandshortselling/WrittenevidenceCDS.pdf. We are also grateful for valuable comments and suggestions received from seminar participants at the European Commission (DG ECFIN), Manchester Business School, EFFAS European Bond Commission Meeting (London), Central Bank of Spain (Madrid), the "Conference on Financial Sector Performance \& Risk" (Bangor), the 20th European Financial Management Association (EFMA) Annual Meeting (Braga), The Finlawmetrics 2011 Sixth International Conference on The New Design of Monetary Policy and Financial Regulation: Economics, Politics and Law (Milan). All errors are our responsability.

Email addresses: g.calice@soton.ac.uk (Giovanni Calice), jing.chen@swansea.ac.uk (Jing Chen), julian.williams@abdn.ac.uk (Julian Williams)
} 
and international bodies such as the International Monetary Fund (IMF) and the European Union (EU) has been a suite of interventions led by the European Central Bank (ECB). ${ }^{1}$

Throughout 2010 the focus of the crisis has been on Greece, Ireland and Portugal where there is concern about the rising cost of financing government debt and the possibility of default on a sovereign debt issuance. On May 2, 2010, the Eurozone countries and the IMF agreed to a EUR 110 billion loan for Greece, conditional on the implementation of a package of severe austerity measures. On May 9, 2010, Europe's Finance Ministers approved the creation of the European Financial Stability Facility (EFSF) aimed at preserving financial stability in Europe by providing financial assistance to Eurozone states in economic difficulty. The objective of the EFSF is to collect funds and provide loans in conjunction with the IMF to cover the financing needs of Eurozone Member States in difficulty, subject to strict policy conditionality. The Greek bailout was followed by a EUR 85 billion rescue package for Ireland in November 2010, and a EUR 78 billion bailout for Portugal in May 2011.

During the crisis, several commentators expressed concern that manipulation of the CDS market by speculative investors was playing a crucial role in exacerbating the liquidity dry up in the market for Greek, Irish, Portuguese and Spanish sovereign debt. In particular,'naked' CDS positions were blamed for driving bond yields on these countries sovereign debt higher during the first half of 2010. In this context, Greece was suggested to have been a victim of short-term speculative short selling practices on its national debt and naked shorting practices in the CDS market.

In this paper, we investigate the potential spillover effects between the credit and liquidity spreads in the Eurozone sovereign bond market and the sovereign credit default swap (CDS) market during the 2010 European sovereign debt crisis. We define two credit spreads, denoted by the suffix CS. First, the difference in the required discount rate on Eurozone members benchmark sovereign debt issuance against a benchmark (in this case equivalent German benchmark bonds). Second, the difference between the CDS spread on benchmark sovereign debt against the CDS spread on equivalent German sovereign debt. In equilibrium, these should co-move almost precisely. We then use the bid-ask spread on the bond and CDS markets to proxy for market depth and transactions costs and hence market liquidity and enter these four variables into a vector model. This is denoted by the suffix LS for liquidity spread. For brevity we utilise the commonly understood equity/foreign exchange parlance bid-ask spread, to refer to the difference between the yield(spread) bid and the yield(spread) ask for the sovereign bond(CDS) market.

Several key results emerge from the analysis. First, we find that whilst the liquidity of the sovereign debt market dries up over the crisis period, the liquidity of the CDS market increases dramatically with spread bids and spreads asked pproaching a one to one ratio.

Second, the transmission effect from the credit spread in th esovereign CDS market to the credit spread on sovereign bond market is, at times, large in magnitude and highly significant for Ireland, Spain, Greece and Portugal.

Third, the significance of the interaction of the CDS liquidity spread and the credit spread on the bond market changes markedly over the sample period. This observation implies that the liquidity of the CDS market does impact the credit spreads and that this mechanism is higher during periods of high market stress, such as immediately after the Bear Stearns rescue and the Lehmen Brothers default.

We believe that our results are of interest to academics, practitioners and of particular relevance to policymakers in forming a better understanding of the information transmission channels between sovereign CDS and sovereign debt markets. In particular the inter-temporal nature of the liquidity spillover should assist policy makers in identifying the epoch during which the market is no longer able to correctly evaluate

\footnotetext{
${ }^{1}$ After August 2007, several interconnected crises occurred. At points, we will refer to the 'US subprime mortgage crisis' which unveiled in August 2007. For the purposes of this study, we restrict this definition to refer to losses incurred by financial institutions on mortgage-backed securities and associated structured derivatives. We define 'credit crisis' and 'credit crunch' as the explosive growth in interbank lending rates, relative to policy rates, during early 2008. These are obviously interlinked. Finally, we refer to the 'Eurozone sovereign debt crisis' as the period of high growth in late 2009 of credit spreads on sovereign debt for several Eurozone countries. For brevity we often use the capitalised term Eurozone to refer to the collection of countries in the euro area with monetary policy conducted by the ECB and operating under the rules of the Eurosystem. Credit spreads, in this context, is the difference in yield between the sovereign bond issuance for a euro area member state and the equivalent maturity German government bond (bund).
} 
the credit premium (as an explosive trend has taken hold). Therefore, dissimilarly from previous studies, our results can be used to explicitly identify potential rates for coordinated interventions in assisting severely financial distressed countries.

The remainder of the paper is organised as follows. $\S(2)$ provides background information on the Eurozone crisis and reviews the related literature on the pricing and liquidity of the bond and CDS market. $\S(3)$ describes our empirical methodology and $\S(4)$ the data pre-processing used in the study. $\S(5)$ contains our analysis of the results whilst $\S(6)$ offers our concluding remarks.

\section{Background and Related Literature}

In our analysis, we utilise a time varying vector autoregression (TV-VAR) to capture the changing relationship between the lagged credit and liquidity spreads for nine countries in the Eurozone. The empirical model treat the evolution of credit spreads and liquidity spreads as being completely endogenous, i.e. the contemporaneous credit and liquidity spreads are on the left hand side of the equation whilst the lagged values and shocks are on the right. The objective is to discern changes in the transmission coefficients (the slope parameters of the model) as the Eurozone crisis has evolved. The model is run on daily indices computed from transaction and industry reported end-of-day data for the bond and CDS markets. To our knowledge this is the first paper to analyse this data in this context.

The basic form of our results is in the form of plots of coefficients on lagged variables that identify particular channels of information. To contextualise our results Table A.1 outlines the timeline of the crisis.

\section{[TABLE A.1 GOES HERE]}

The primary risk mechanism involved in triggering the Eurozone sovereign debt crisis is that each individual country, upon joining the Eurozone, effectively gave up the right to inflate (and hence depreciate their currency) their way out of financial distress should the amount and cost of borrowing suddenly rise to unsustainable levels. This implies that countries, in an identical manner to firms, could in theory completely default on sovereign debt issuances. Indeed, the collapse of Lehman Brothers in 2008 revealed that the so-called too-big-too fail institutions could default on their debt and as a consequence credit spreads on corporate debt increased rapidly during the 2007-2010 period.

Prior sovereign defaults, for instance Argentina in 2001, were caused by a similar ceding of seignorage revenue and a hard constraint on expansion of the monetary base. In the case of Argentina, a currency board with the United States was fixed with supposedly 100\% US Dollar reserves. When the currency board was broken and the Argentinian peso devalued, several US Dollar backed sovereign debt issuances defaulted, with low recovery rates.

Notably, the reasons for the high levels of borrowing for certain members of the Eurozone in the aftermath of the financial crisis are not uniform. Countries such as Greece and Italy have consistently recorded high levels of government borrowing to ensure continuation of provision of public services and public sector pay and conditions settlements. The major issue for Ireland has been in the form of providing assurances for a large financial sector that has suffered great losses during the financial crisis.

\section{[TABLE A.2 GOES HERE]}

During the crisis period we can observe a major change in many macroeconomic indicators for the Eurozone countries members. In Table A.2, we present some of the background statistics that characterize the economic problems faced by selected Eurozone members during the 2007-2010 period and how this epoch differs from the previous seven years since the common currency was formed.

The most striking statistic is annual GDP growth. In fact, during 2009 every single country recorded a contraction in output. The Eurozone as a whole, that had seen 2.16\% trend growth 1999-2006, suffered 
a $4.10 \%$ contraction during 2009 . Output growth in 2008 was virtually stagnant, with Ireland and Italy exhibiting a contraction one year before the rest of the Eurozone members. The consequences on the makeup of the economy are documented in the breakdown of the various statistics. For default risk the most obvious indicator is the size of the government deficit and the direction of growth in government revenue. The conditions for both of these indicators deteriorated markedly during the 2007-2010 period. Revenue has dropped for the Eurozone as a whole and markedly for certain countries such as Ireland, Portugal and Spain. Over approximately the same period, the total government deficit for the Eurozone has increased to around EUR 0.5 trillion.

The impact on credit spreads on Eurozone sovereign debt has been marked. Figures A.1 to A.4 present the time evolution of the daily credit spreads for a selection of countries in our sample.Plots are in equivalent basis points. Therefore, the reader should divide by 1,000 to convert to decimals. The top plot presents the spread for 5-year bonds and the lower plot for 10-year bonds. It is important to note that there has been a homogeneous rise in the yield for each country over the German benchmark as the heightened level of default risk discounts the par value of sovereign debt.

Simultaneously, we can see some radical shifts in the liquidity spread of the two traded instruments, see Figures A.1 to A.4 for examples. The bid-ask spread for the bond and CDS fluctuates considerably during the crisis period and it is the information transmission between the credit and liquidity spreads for the two markets that is the primary focus of this paper.

An eminently sensible standpoint to take is that CDSs are simply a short position in a defaultable bond. This observation is an entirely consistent argument because once protection equivalent to the par value of the underlying bond has been purchased, then the portfolio of underlying and derivative should replicate the risk free rate (it is indeed a synthetic risk free rate). Therefore, the spread on the yield of the defaultable bond over the risk free rate should in effect be replicated by the cost of holding the protection (i.e. there is a risk premia in holding bonds and under arbitrage free pricing the cost of protection should fully offset this premia). However, recent studies (see, for instance, Calice et al. (2011)) suggest that trading strategies in corporate CDS generate far higher returns than the equivalent cost of the premia.

The ability to construct replicating positions by combinations of short and long positions in the defaultable bond, risk free rate and CDS markets is complicated by variations in the underlying liquidity of each market and the non-aligned incentives created by holding one of the three instruments exclusively, e.g. a short naked CDS position. The incentive structure is easy to understand, if an investor is able to create a highly leveraged speculative bet on default (by use of a naked CDS position for instance, which often requires no initial margin). In this situation, it would then be highly desirable to alter the liquidity of the alternative markets to suit an investor's purposes, (e.g. by withdrawing liquidity from the defaultable bond market and driving up required yields and complicating restructuring of distressed debt).

Manipulation of market liquidity is often the primary mechanism through which speculative attacks are channeled and in this case the object of interest is the bilateral liquidity structure of the sovereign debt market and the sovereign CDS market. A comprehensive survey of the speculative attack literature is beyond the scope of this study and, at present, there is no direct evidence from regulatory investigations to suggest that this type of strategy has been implemented by certain market participants. Thus, we touch upon a few contributions that underpin the prevailing academic perspective on the effects of liquidity, asset prices and credit instruments.

An important question at this juncture is: 'does the basis point difference in the yield (spread) bid-asked capture the true liquidity of the bond(CDS) market?' The bid-ask spread is one of a suite of liquidity proxies commonly used in the academic literature. Unfortunately for bond and CDS markets volume information is not as readily available as it is in the equity market. Therefore, robustness checks with alternative measures are not easily implementable.

Roll (1984) presents an early assessment of the information content of the bid-ask spread, identifying the components of the transactions costs of trade. Chordia et al. (2001) and later in Chordia et al. (2008) the bid-ask spread is identified as an important proxy for liquidity. In a direct antecedent of our approach Chordia et al. (2003) uses the bid-ask spread is used as a proxy for the liquidity of both the stock and bond market and estimates a vector autoregressive model of their joint dynamics. In the case of bond and CDS markets, the bid-ask spread or yield bid-asked is in fact the only available liquidity proxy as trade volumes 
are known in only a small proportion of the transaction history.

This paper complements the current literature by focusing on the interactions between liquidity and credit spreads in the sovereign CDS and bond markets. While a comprehensive survey of this literature is beyond the scope of this study, we touch upon a few contributions that underpin the prevailing academic perspective on the effects of liquidity on asset prices. Early studies about liquidity effects have been focused on traditional securities, such as stocks and bonds, for which adequate data is available to proxy or estimate liquidity effects. As a result, the focus of the mainstream literature on liquidity is on these markets, rather than emerging securities such as CDSs.

In Chen et al. (2007) the relationship between corporate bond liquidity and yield spreads is analysed for corporate bond issuances. Three models of the bid-ask spread are proposed and estimated over a dataset of 4,000 corporate bonds spanning both investment grade and speculative issuers. Their results suggest that illiquidity bonds leads higher yield spreads and an increase in liquidity results in a decrease in yield spreads. Additionally, they point out that the level of yield spreads cannot be fully explained by default risk per se.

A similar study by Ericsson and Renault (2002) also reveals the association of corporate bond liquidity and yield spreads. They entertain a structural bond valuation model to illustrate the influence of liquidity risk on the yield spreads of the bond. The major findings are that liquidity spreads are positively related to the default components of yield spreads and liquidity spreads decrease with the time to maturity.

Liquidity has been reported as an important factor influencing prices in the Treasury bond market. Amihud and Mendelson (1991) attempt to examine the relationship between asset liquidity, yield spreads and maturities by using securities data from U.S. Treasury notes and bills and provide a strong evidence of liquidity effects on asset prices. Their results show that there is a significant and negative association between yield to maturity and liquidity of notes. Additionally, yield spreads decrease with time to maturity.

There are a few studies that use CDS spreads as a benchmark to control for credit risk in order to study liquidity effects in bond markets. Longstaff et al. (2005) use the price of CDS contracts as information to measure the default and non-default risk components in corporate spreads and find that default risk is the main determinant of bond credit spreads. With respect to the non-default component, they find that this component is time varying and there is a strong relationship between the non-default component and the evaluation of bond-specific illiquidity. Moreover, changes in the non-default component are related to measures of Treasury yield spreads as well as to measures of the overall liquidity of fixed income markets. This study is the primary source of inspiration of our framework, delineating credit spreads as the yield spread over the appropriate benchmark and the liquidity spread as the daily average of the yield bid to yield ask.

In support of the findings in Longstaff et al. (2005), Han and Zhou (2007) examine the size of nondefault components in corporate bond yield spreads and find a relationship with bond liquidity. They use intraday transactions data and the term structure of CDS to measure bond liquidity and default components, respectively. Their results show that the non-default components positively and significantly relate with bond illiquidity for investment-grade bonds but not for the speculative-grade segment of the market. This result is analogous to Longstaff et al. (2005). In addition, Han and Zhou (2007) suggest that the non-default component of bond spreads fluctuate with macroeconomic and financial variables such as the Treasury term structure and stock market implied volatility.

In an extensive empirical study Mahanti et al. (2008) relates CDS credit and liquidity spreads to bond credit and liquidity spreads. The authors develop a new method, termed 'latent liquidity', to investigate whether expected liquidity is priced in the corporate bond market. They first study the difference between CDS premium and corporate bond yield, the CDS-bond basis, which is used to measure the non-default component in the corporate bond yield. They primarily focus on the liquidity impact on corporate bond prices and show that liquidity plays a critical role in the CDS-bond basis and bond yield. Their results also lend support to the hypothesis that higher liquidity levels are generally associated with a lower value in the non-default component of corporate bond yield spreads and higher bond prices.

In contrast to Mahanti et al. (2008), De Jong and Driessen (2007) introduces Treasury bond liquidity and equity market liquidity as significant factors influencing corporate bond spreads to discuss the liquidity impact on the pricing of corporate bonds. They provide evidence of a positive relationship between corporate bond returns and the fluctuations in the equity and bond market liquidity measures though time-series 
regressions. In terms of cross-sectional regression, their results suggests that the liquidity risk premium is a factor that does have an impact on the level of corporate bond yields, the latter of a similar size to that of the market risk premium.

A recent contribution about the liquidity effect on corporate bond is offered by Wang (2009). The author develops a new approach which eliminates the credit risk component, the fixed effect as well as the time effect in corporate bond returns and only consider the liquidity component in the corporate bond. As a result, the bond yield difference should be due only to the liquidity component. Regression results have confirmed this assumption. However, most of the liquidity proxies have high marginal effects on the liquidity component for both investment and speculative grade bonds regardless they can only explain a fractional part of the difference in the liquidity components.

For instance, Bongaerts et al. (2011) develops an asset-pricing model LCAPM based on the Acharya and Pedersen (2005) model to test for CDS contracts expected liquidity and liquidity exposure. They use 300,000 CDS bid and ask quotes and a sample period spanning from 2000 to 2006. The repeated sales methodology is adopted to explore a CDS portfolio level and the bid-ask spreads are used to measure liquidity. Their main results from a two-step regression suggest that first, credit risk and liquidity are significant determinants in CDS contracts pricing and the liquidity premium can be ascribed to the protection seller. Second, there is an association between expected excess CDS returns and expected loss of CDS portfolio. Third, the expected liquidity effect exceeds the liquidity risk effect.

In contrast to sovereign bond markets, liquidity spillovers in corporate bond markets have been studied extensively. For instance in Tang and Yan (2006) data from the corporate bond, stock, option and CDS markets is used to compute correlations between liquidity measures. The major finding is that the role of a common liquidity factor cutting across these markets is more important than generally assumed, in particular for the CDS market. Illiquidity in CDS markets is found to spillover into the bond, stock and option markets and leads to a statistically significant increase in credit spreads.

The extent and nature of trading in the CDS market and its impact on liquidity is empirically investigated in Acharya and Engle (2009). Using a set of trade-level data for North American single-name CDS provided by DTCC and Markit the Amihud and Mendelson (1991) measure of the ratio of price fluctuation to turnover is computed. Analysis of the time-series variation in CDS market liquidity indicates substantial fluctuations over the 2007-2008 sample period.

The market liquidity effects and liquidity spillovers between the CDS, the corporate bond and the equity market is examined in Jacoby et al. (2009). Results from vector auto-regressions illustrate the presence of a common component between the stock market and both the CDS and the corporate bond market whilst no common component is found specifically between the CDS and the bond market. Moreover, evidence of a liquidity spillover only from the equity market to the CDS market. Finally, the study documents a time lag in liquidity shocks from the CDS to both corporate bond markets and stock markets.

A number of recent studies have addressed the comovement of CDS markets, bond markets and equity markets. Bystrom (2005), for instance, finds a linkage between stock indices return volatilities and CDS spreads for a set of sub-indices of the European iTraxx index. The empirical results show that CDS spreads have a negative relation with stock prices whereas they are positively related to stock price volatility. The European CDS market and its relationship with the stock market has been investigated by Norden and Weber (2004), who find that the CDS market is sensitive to equity market movements. Furthermore, CDS spreads are found to be negatively related to stock returns.

Norden and Weber (2004) also points out that the CDS market has a leading role in price discovery for equity prices. Moving back to the bond and CDS market lagged and contemporaneous interactions Zhu (2006) provides a direct confirmation of the relationship between bond spreads and CDS spreads. The important finding, in our context, is that both spreads change in the same direction in the long-term while in the short-term this correlation is found not to be identical.

In respect of liquidity spillovers Buhler and Trapp (2009) examines credit risk and liquidity premia for both bond and CDS markets. One important result from this study is that the liquidity of the CDS market drives a far less explicit premia than the bond market. Furthermore, the average liquidity in the subinvestment grade CDS market is higher than the corresponding premium in the investment-grade segment of the CDS market. We interpret these results as suggesting that the provision of liquidity to the CDS 
market does not necessarily follow the standard conventions. More specifically, we suggest that speculative trading maybe more prevalent than trading to simply hedge default risk.

\section{Methodology}

For our analysis we utilise a variation on the standard vector autoregression methodology using a time varying coefficients specification. The VAR model contains four equations, two for the credit spreads in the bond and CDS markets and two for each markets liquidity spreads.

There are two primary benefits to this approach. First, the model treats all of the variables as being part of an endogenous vector process, therefore negating issues of exogeniety. Second, the time varying coefficients structure allows us to capture any structural breaks that might be present in the dataset.

\subsection{Econometric Specification}

A serious issue that arises when dealing with interest rate related data is that it is commonly found to be near integrated to unity, or $I(1)$. However, there is a substantial empirical evidence to suggest that structural breaks play a role in under rejection of the null of a unit root. The nature of potential structural breaks in bond yields data is unclear. For instance, crash breaks are typically found to be changes in intercept. Yet, a fundamental change in the liquidity dynamics of a country's bond markets (particularly, during a financial crisis) may reveal itself in a very different manner. To capture this potentially time varying effect, we propose and implement a recursive and iterated coefficients model. The obvious alternative to this least squares approach would be the adoption of a state space model to generate a fully random stochastic vector that describes the evolution of the coefficients. Experimentation with such models has yielded mixed results. First, we have found in preliminary data analysis that operating at the daily frequency reduces our sample and results in critical issues such as computing correct standard errors and general over fitting.

Use of a higher frequency data set is difficult as the CDS market is plagued, in its early phases, by intraday stale prices and high levels of microstructure contaminants and broken transaction information (missing volumes and bid-offer information). Consequently, we propose an augmented multivariate least squares regression estimator over daily aggregate data that explicitly accounts for heteroskedasticity, autocorrelation and break points. The estimator has a single simple bandwidth (nuisance) parameter that dictates the memory of the model and this parameter is easily optimised using maximum likelihood or some other penalty function approach (for example, the Diebold and Mariano (1995) approach or the rolling versus recursive Giacomini and Rossi (2010) forecast breakdown).

We follow in the spirit of the recursive/rolling window approach from Giacomini and Rossi (2010) to build our time varying VAR models. For a sample of size $N$, an initialisation period $t_{0}, t_{I}$ is selected. Over this period, we use an approach in which we estimate a standard recursive coefficients model with increasing sample size. Once the recursion has moved beyond $t_{I}$, the model data is weighted using a kernel function $k(\cdot)$. For most kernels this weighting results in a natural truncation at lag length $T$. For instance, using an exponentially weighted moving average, with decay parameter $h$, the lag length for $99 \%$ of the sample weight is $T=\frac{\log 0.01}{\log 1-h}$. Alternatively the weighting could be chosen equal over an arbitrary rolling window $T$. This is subject to the discretion of the econometrician. From time $t_{T}$ onwards, the model is estimated over a rolling sample window equal to $t-T, t$. In practice, we utilise the exponential weighting and restrict the decay to the domain $[0.85,0.95]$ in keeping with the suggestion in Arvastson et al. (2000). The results vary by only a small degree and for fine tuning purposes only the results reported here are for the decay parameter with the smallest root mean squared error over the whole of our sample period.

Consider a representative country from our sample of nine Eurozone members and maturity, we will use 5- and 10-year benchmarks as representative maturities. To capture the time varying spillover effect between the bond and the CDS market we compute the $B O N D C S_{t}$, the sovereign bond credit spread, the $C D S C S_{t}$, the CDS credit spread, the $B O N D L S_{t}$, the sovereign bond liquidity spread and finally the $C D S L S_{t}$, the 
CDS liquidity spread. These are computed as follows:

$$
\begin{aligned}
B O N D C S_{t} & =B O N D_{t}-B O N D_{D E, t} \\
C D S C S_{t} & =C D S_{t}-C D S_{D E, t} \\
B O N D L S_{t} & =B O N D B I D_{t}-B O N D A S K_{t} \\
C D S L S_{t} & =C D S B I D_{t}-C D S A S K_{t}
\end{aligned}
$$

where $B O N D_{t}$ is the mid-quote yield (or discount premia) for sovereign debt (of either a 5 - or 10-year maturity) measured in basis points. $C D S_{t}$ is the credit default swap rate, in basis points. $B O N D_{D E, t}$ and $C D S_{D E, t}$ are respectively the yield and CDS spread on German sovereign debt of 5- and 10-year maturity. $B O N D B I D_{t}$ is the bid yield in basis points for sovereign bonds and BONDASK $K_{t}$ is the ask yield for sovereign bonds, again converted to basis points. Finally, $C D S B I D_{t}$ and $C D S A S K_{t}$ are, respectively, the bid and ask spreads for 5- and 10-year sovereign CDS. For brevity, we refer to each countries model by maturity, i.e. the 5-year Greek model. For each credit and liquidity spread we use a daily average from the transaction history, if available, or from an average of end of day vendor data. Recall that each of the variables on the right hand side is already in basis points. Therefore, note that we do not utilise logarithmic ratios or divide by the mid quote as it is standard practice in the equity literature, when dealing with equity prices, see for instance Longstaff et al. (2005) for a discussion.

\section{An Endogenous Model of Price-Liquidity Formation}

In this paper, we provide results for an endogenous model of credit and liquidity spread formation using a time varying VAR model of price and liquidity variables for sovereign bond and CDS markets during the crisis. We have also tested an exogenous model of liquidity creation and these results can be found in Calice et al. (2011). Consider the following four dimensional vector autoregressive process

$$
y_{t}=\left[B O N D C S_{t}, C D S C S_{t}, B O N D L S_{t}, C D S L S_{t}\right]^{\prime} .
$$

Alternative specifications can include volume and realised volatility (ex-post quadratic variation) measures, see Chen et al. (2011) for an example of this type of TV-VAR liquidity model in a structural setting. The objective of the study is to compute the following time varying coefficients model:

$$
y_{t}=\tilde{B}_{t} y_{t-1}+\tilde{\mu}_{t}+u_{t}
$$

where $\left\{\tilde{B}_{t}, \tilde{\mu}_{t}\right\}$ are, respectively, a matrix of slope coefficients for the lagged parameters and a vector of intercepts. Setting $\tilde{B}_{t}=\left[\beta_{i, j}\right]$ and $\tilde{\mu}=\left[\mu_{i}\right]$, the system of equations in the model is as follows:

$$
\begin{aligned}
B O N D C S_{t} & =\beta_{1,1, t} B O N D C S_{t-1}+\beta_{1,2, t} C D S C S_{t-1}+\beta_{1,3, t} B O N D L S_{t-1}+\beta_{1,4, t} C D S L S_{t-1}+\mu_{1, t}+u_{1, t} \\
C D S C S_{t} & =\beta_{2,1, t} B O N D C S_{t-1}+\beta_{2,2, t} C D S C S_{t-1}+\beta_{2,3, t} B O N D L S_{t-1}+\beta_{2,4, t} C D S L S_{t-1}+\mu_{2, t}+u_{2, t} \\
B O N D L S_{t} & =\beta_{3,1, t} B O N D C S_{t-1}+\beta_{3,2, t} C D S C S_{t-1}+\beta_{3,3, t} B O N D L S_{t-1}+\beta_{3,4, t} C D S L S_{t-1}+\mu_{3, t}+u_{3, t} \\
C D S L S_{t} & =\underbrace{\beta_{4,1, t} B O N D C S_{t-1}+\beta_{4,2, t} C D S C S_{t-1}}_{\text {Lagged Credit Spread Coefficients }}+\underbrace{\beta_{4,3, t} B O N D L S_{t-1}+\beta_{4,4, t} C D S L S_{t-1}}_{\text {Lagged Liquidity Spread Coefficients }}+\mu_{4, t}+u_{4, t}
\end{aligned}
$$

There are a variety of ways to estimate the time varying coefficients in this model. These approaches range from simple rolling windows to state-space models with specific stochastic processes assumed for the time varying coefficients (e.g. a random walk or stationary first order autoregressive).

The motivation for our estimator stems from the need for a more robust approach to recursive estimation that complements the standard suite of Kalman filter/state space estimators. In our initial study we have utilised a standard unscented Kalman filter model with random walk state space. However, the issue of 'over-fitting' is particularly critical for state space based models. Specifically, the variation between the time varying coefficients for the model with intercept versus the model with intercepts suppressed suggested that the Kalman filter over ascribed the local dynamics (from the Kalman gain) and under represented the long 
run structure. There is no theoretical foundation to why this effect should be present in the data. Yet, this issue becomes particularly serious when the series is effectively a set of locally stable linear models with permanent structural breaks in the intercept, $\tilde{\mu}_{t}$, and slope, $\tilde{B}_{t}$, coefficients at specific time intervals. ${ }^{2}$

We have therefore developed a least squares based alternative to the Kalman filter that is robust to structural change, whilst being able to capture local stability in the coefficients. We call this approach recursive and iteratively weighted least squares (RI-WLS), which can be regarded as a specific class of the extended least squares approach. More specifically, the model is a multivariate extension of the single equation autoregressive model of Arvastson et al. (2000) which is a standard autoregressive model with time varying coefficients estimated with exponential forgetting. In addition to the increase in dimension to the multivariate context, we also add a robustness component to deal with the potential outliers caused by the sudden appearance of a structural break. This is the iterative re-weighting at each time step. Consider the multivariate regression whereby

$$
y_{t}=B_{t} x_{t}+u_{t}
$$

such that $B_{t}=\left[\tilde{B}_{t}, \tilde{\mu}_{t}\right]$ and $x_{t}=\left[y^{\prime}{ }_{t-1}, 1\right]^{\prime}$. The data is gathered into rolling matrices $X_{t}$ and $Y_{t}$, with rows

$$
Y_{t}=\left[y_{t-T}^{\prime}, \ldots, y_{t}^{\prime}\right]^{\prime}, \quad X_{t}=\left[x^{\prime}{ }_{t-T}, \ldots, x^{\prime}{ }_{t}\right]^{\prime}
$$

For each time step, the estimated time varying coefficient matrix $\hat{B}_{t}$ is computed using an iteratively reweighted least squares approach. First, the data matrices $X_{t}$ and $Y_{t}$ are element by element weighted using kernel weights $H^{x}$ and $H^{y}$. In the simplest case, these are equivalent sized matrices of one. Alternatively, the matrices can be weighted using a linear decay or exponentially weighted decay. We choose an exponentially weighted moving average with decay coefficient $h$, a single time invariant nuisance parameter. The first iteration of $\hat{B}_{i, t}$ is computed by ordinary least squares

$$
\hat{B}_{i=1, t}=\left(\left(X_{t} \circ H^{x}\right)^{\prime}\left(X_{t} \circ H^{x}\right)\right)^{-1}\left(X_{t} \circ H^{x}\right)\left(Y_{t} \circ H^{y}\right)
$$

where $\circ$ is the Hadamard product and the kernel weighted residuals $\hat{E}_{i=1, t}=Y_{t} \circ H^{y}-\left(X_{t} \circ H^{x}\right) \hat{B}_{i=1, t}$ and the diagonal elements of the outer product are collected. The iterative weighting, $W_{i}$, is computed in the standard manner $W_{i}=\operatorname{diag}\left(\left|\operatorname{diag}\left(\hat{E}_{i, t} \hat{E}_{i, t}^{\prime}\right)\right|^{p-2}\right)$. The updated WLS is now

$$
\hat{B}_{i, t}=\left(\left(X_{t} \circ H^{x}\right)^{\prime} W_{i, t}\left(X_{t} \circ H^{x}\right)\right)^{-1}\left(X_{t} \circ H^{x}\right)^{\prime} W_{i, t}\left(Y_{t} \circ H^{y}\right)
$$

Once again, $\hat{E}_{i, t}=Y_{t} \circ H^{y}-\left(X_{t} \circ H^{x}\right) \hat{B}_{i, t}$ and the next iteration of $W_{i}$ is computed. At each iteration $\lambda_{i}=$ $\left\|\hat{B}_{i=n, t}-\hat{B}_{i=n-1, t}\right\|_{F}$ is computed. $|\cdot|_{F}$ indicates the Frobenius norm, when $\lambda_{i}<c$ the algorithm terminates and the iterated value of $\hat{B}_{t}$ is recorded. The array of coefficients $\mathcal{B}=\left[B_{t}\right]$ is called the transmission function. The final set of model residuals for the model are collected $y_{t}=\hat{B}_{i, t} x_{t}+\hat{u}_{t}$. Setting the covariance matrix to be $\hat{\Sigma}_{t}=T^{-1} \hat{E}_{t}^{\prime} \hat{E}_{t}$, the standard errors are computed in the standard fashion by $\operatorname{cov} v e c B_{t}=$ $\left(\left(X_{t} \circ H^{x}\right)^{\prime} W_{t}\left(X_{t} \circ H^{x}\right)\right)^{-1} \otimes \hat{\Sigma}_{t}$.

One of the most useful aspects of this approach is that all of the standard VAR model decompositions and diagnostic tests (block exogeneity and causality) are testable for each epoch of the model. For our purposes, it is critical detecting whether structural breaks are present in the data and if the local stochastic trend (for each time iteration) is explosive. We have chosen a first order VAR model therefore inference is easily discernable directly from the evolution of the coefficients.

\subsection{Inter-temporal Model Stability, Stationarity and Structural Breaks}

The eigenvalues of the time varying matrix $\tilde{B}_{t}$ offer valuable information on the instantaneous stability of the autoregressive model. Consider the time varying eigenvalues of the $4 \times 4$ slope matrix $\tilde{B}_{t}$, ordered from

\footnotetext{
${ }^{2}$ We have conducted Monte-Carlo experiments creating artificial data sets with this effect. The standard Gaussian Kalman filter is found to have a bias in ascribing variation in the slope coefficients to the intercept and these studies are available from the authors.
} 
largest to smallest as $\left\{\lambda_{\max , t}, \lambda_{2, t}, \lambda_{3, t}, \lambda_{\min , t}\right\}$. We have imposed a first order VAR on the time varying coefficients. Therefore, the eigenvalues of this matrix correspond directly to polynomial roots of the VAR process. If the range of $\lambda_{\max , t}$ to $\lambda_{\min , t}$ is within the unit circle then the instantaneous static VAR at time $t$ is stationary. A root equal to one indicates the presence of at least one random walk in the vector system. A root greater than one (recall these are inverse roots) indicates an explosive trend in at least one of the variables.

We will see that computing this test statistic is important, as the data for certain time periods, appears not only non-stationary, but non-stationary with an explosive trend, (i.e. potentially some variables are integrated at $I(2)$ or above). This causes particular problems for inference and we will address the issues caused by these artefacts in particular with respect to the instability in the residual variance-covariance matrix.

A helpful by-product of the recursive regression approach is that a standard matrix equality test can be used to extend the standard univariate variance break point tests for structural breaks, by use of a Wishart style covariance equality test, see Williams (2011) for a full overview of the test. Setting $\hat{\Sigma}_{t}=T^{-1} \hat{E}_{i, t}^{\prime} \hat{E}_{i, t}$ to be the conditional covariance matrix and $\hat{\Sigma}=m^{-1} \sum_{t=1}^{m} \hat{u}_{t} \hat{u}_{t}^{\prime}$. For a candidate break point $\tilde{t}$ the equality test is of the form

$$
\hat{\Sigma}_{t+1}=\hat{\Sigma}_{t+2}=\ldots=\hat{\Sigma}_{t=m}=\hat{\Sigma}
$$

versus

$$
\hat{\Sigma}_{\tilde{t}+1}=\hat{\Sigma}_{\tilde{t}+2}=\ldots=\hat{\Sigma}_{t=m}=\hat{\Sigma}
$$

for some prior sample point $\tilde{t}<t$ (see Muirhead (1981) for a full exposition). Setting $U_{t}=\left[u_{t-T}^{\prime}, \ldots, u_{t}^{\prime}\right]^{\prime}$ and $U_{\tilde{t}}=\left[u_{\tilde{t}-T}^{\prime}, \ldots, u_{\tilde{t}}^{\prime}\right]^{\prime}$. We know from standard statistical theory that for a block of normally distributed zero centered residuals of length $\tau$ with sample covariance matrix $\hat{\Sigma} \tau \hat{\Sigma} \sim \mathcal{W}(\tau, n, \tilde{\Sigma})$, therefore a multivariate test of covariance equality will be of the form:

$$
\Lambda^{*}=\frac{\left(\operatorname{det} A_{t}\right)^{t}}{\left(\operatorname{det} A_{\tilde{t}}\right)^{m-\tilde{t}}} \cdot \frac{(t)^{\frac{1}{2} n(m-\tilde{t})}}{(m-\tilde{t})^{\frac{1}{2} n(t)}}
$$

where $A_{t}=U_{t}^{\prime} U_{t}$ and $A_{\tilde{t}}=U_{\tilde{t}}^{\prime} U_{\tilde{t}}$ for a single candidate partition at $t$. Where $n$ is the dimension of the VAR (in this case four). In the case that $U_{\tilde{t}}$ and $U_{t}$ are draws from a multivariate normal distribution, the distribution of $-2 \log \Lambda^{*}$ is known to be $\chi^{2}(\nu)$, where $\nu=\frac{1}{2} n(n+1)(1+m)$ plus an adjustment for the error in estimating the underlying VAR. We utilise the approach of Williams (2011) to generate the adjusted significance bounds using Monte-Carlo to augment the asymptotic cases presented in Muirhead (1981).

The discretion of the econometrician is in choosing the minimum size of the proportion of the sample between $\tilde{t}, t$ and $m$. In our case, we initially select a single partition and try to find a first break point for the VAR starting January 1, 2007 and then roll forward with minimum distance between variance breakpoints of $10 \%$ of the sample size. Table A.7 presents the first detected breakpoint for each country for the 5- and 10-year maturity debt. Note that the most useful aspect of this is in identifying the need for a time varying coefficients model versus a static model and every model for every country exhibits at least on breakpoint during the sample.

\section{Data Sources and Cleaning}

The data set is sourced from Thomson-Reuters Tick History and DataStream. Sovereign bond data is collected using the 'Super RICs' or Reuters Information Codes described in Table A.3. The super-RICs pull trades reported by various data vendors on instruments in the tag range set by the code, i.e. AT5YT=RR literally means pull all yields on traded bonds with a 5-year maturity from the daily collection date for Austrian government bonds. In practice the retrieved maturities are for sovereign bonds in the forward benchmark range. These are bonds that mature relative to the month. For instance, the earliest maturity 
of trade for $\mathrm{AT} 5 \mathrm{YT}=\mathrm{RR}$ would be 4 years 11 months and the latest would be 5 years 1 month. The 5 year yields for the bid, ask and mid quote are then interpolated. We use the same approach for the CDS market. However, aggregation is much more complex. Multiple data vendors provide an array of intra-day and end-of-day information. To compute the daily credit and liquidity spread indices, we utilise arithmetic means, medians and standard deviations of the spread-bid spread-asked and the mid-quotes for each end of day sample. Only traded CDS are used in the study. Note also that the super-RICs automatically reject any inferred spreads taken from the bond market. Thus, our CDS credit and liquidity spread indices differ slightly from those available from CMA through Datastream. Unfortunately, Thomson-Reuters and CMA have ceased to provide CDS data through DataScope, DataStream and TickHistory after October 1, 2010. Thus, this date identifies the end of our sample period.

\section{[TABLE A.3 GOES HERE]}

We collect all traded sovereign bonds with a maturity of 5- and 10-years for the countries selected in the sample. Originally all Eurozone countries were included in the sample. However, CDS have only been actively traded on ten countries for a sufficiently long period to enable the analysis. These countries are Austria, Belgium, France, Germany (the benchmark), Greece, Ireland, Italy, Netherlands, Portugal and Spain.

\section{Bond Data}

We collect the tick by tick quotes and trades on sovereign bonds from January 1, 2000 to October 1, 2010, resulting in a full sample consisting of 943 trading days. For the quotes and trades we compute the bid yield, the ask yield and the transacted yield. The frequency of the time series analysis is driven by the tick updates from the CDS market, which is often sparse at points during the day. We therefore aggregate the intraday ticks to a daily frequency. We stratify them by bond maturity (i.e. closest to 5-years and closest to 10-years similarly to the bond data) and compute the logarithmic average spread of the transacted bond yields for each country over the equivalent German bond. Next, we aggregate the yield bid and ask to compute the average logarithmic daily liquidity spread for the 5- to 10-year sovereign bonds, again equally weighted over maturities. We have a longer data series for the bond tick data running to May 20, 2011, however our analysis is restricted by the availability of the CDS data.

\section{CDS Data}

The CDS data is a mix of pre-aggregated and end-of-day sampled CDS transactions reported by CMA to Thomson-Reuters. Unfortunately CMA have stopped reporting CDS end-of-day or time and sales transaction data to Thomson-Reuters through DataStream or TickHistory from October 1, 2010. As CMA are the primary data gatherer for all sub sources, we are unable to include the bailout of Portugal in our sample.

\section{[TABLE A.4 GOES HERE]}

Some of the transaction data is available, although this is a small fraction of the total daily OTC trades. To obtain a complete overview of the 'true' liquidity of the market, CDS data needs to be extracted from various over the counter (OTC) sources. Table A.3 outlines our super RIC codes that extract the individual transaction data. In addition, we report the DataStream codes used to collect the end-of-day dataset. Further efforts to source equivalent trade data are ongoing and are probably conditional on solution to the investigation of CDS data reporting by the European Union. ${ }^{3}$

\footnotetext{
${ }^{3}$ See: Timing of European CDS Probes Piques Interest, by Kate Burne, Dow Jones Newswire May 3, 2011.
} 
Table A.4 presents the complete list of OTC sources used to compile these daily statistics. The CDS data is divided into three parts: the spread asked, spread bid and spread transacted. To proxy for CDS market liquidity, we compute the logarithmic ratio of the daily average spread bid to the spread asked. To quantify the risk premium, then we compute the log ratio of the daily average transacted spread for each sovereign CDS relative to the transacted CDS spread using the German government's federal bond as a benchmark. For the bond data we are able to supply the full descriptive outline for the cleaning procedures.

[TABLE A.5 GOES HERE]

The various data sets are incomplete over the 2004-2010 time period. Therefore, we have manually cleaned and amalgamated the sources to produce a complete daily frequency bid, ask and mid quote CDS for the nine countries plus the German benchmark in the sample. In our analysis, we have run the TV-VAR over the longest possible time period given the available data for the CDS market. This is generally from January 1, 2004 for all countries except for Ireland and Greece (January 1, 2003) and Germany (August 15, 2005). Therefore credit spreads for sovereign CDS are limited to the 1,339 days from August 15, 2005 to October 1, 2010. Furthermore, visual inspection of the data from August 15, 2005 to January 1, 2007 (see the Internet Appendix) shows that stale prices and explosive spreads (usually from canceled trades, which we can see in the small amount of available tick data) are highly prevalent. Consequently, we truncate the reported time varying models to the January 1, 2007 to October 1, 2010 period.

\section{Analysis}

The complete set of results plots is contained within the Internet Appendix. This consists of sixteen plots for the group of nine countries, and a set of 144 individual plots, for the evolution of the various coefficients. This number increases to 288 when including the robustness check by imposing the restrictions on the intercept terms $\tilde{\mu}_{t}$ in the system. All plots for the TV-VAR models for the various specifications are catalogued in the Internet Appendix. We have attempted to distill only the most economically important facets of the large number of results obtained from the study. Therefore, for our discussion, we have selected only a limited number of figures from the pool. These are as follows: the time evolution of the 5- and 10-year credit and liquidity spreads for Greece, Ireland, Netherlands and France; the time varying roots of the TV-VAR model for the 5-year TV-VAR for Greece and Portugal; the time varying coefficients for the 5-year models for all four equations for Greece and Ireland. The time varying coefficients for the first equation for Portugal, Spain and France for both the 5- and 10-year models.

Specific hypothesis testing in this context is somewhat difficult. We present breakpoint tests based on equality of variance approaches, which have testable predictions relative to the events detailed in Table A.1. The TV-VAR coefficients are presented with time varying error bounds, covering \pm 2 standard errors. This obviously allows us to construct a test as to whether the coefficient is indistinguishable from zero at this point in time. Where possible we have used either robust iterative re-estimation or Monte-Carlo simulation to augment standard errors and sample critical boundaries.

\section{Descriptive Statistics of Credit and Liquidity Spreads}

Table A.5 presents the arithmetic mean and standard deviation of the credit and liquidity spreads for each country. For each country we provide the whole sample and the post 2007 average and standard deviations. Notable results in this table are the explosive standard deviations, in addition to the anticipated rise in the average credit spreads, for all countries, with the post 2007 variance being either slightly or substantially larger. Greece (231.272 for the whole sample and 281 for the post 2007 period), Portugal (72.744 and 83.308) and Ireland (85.595 and 92.443) for the credit spreads on 5-year sovereign bonds exhibit substantial rises. Interestingly, the rise in the CDS credit spread is not necessarily higher than the bond credit spread. For the liquidity spreads, all countries experience a rise in the credit spreads, on average. 
However, when plotting the evolution of these spreads it turns out that both the liquidity and bond spreads are highly persistent processes.

[TABLE A.5 GOES HERE]

\section{[A PANEL WITH FIGURES A.1 to A.4 GOES HERE]}

\section{[A PANEL WITH FIGURES A.5 to A.8 GOES HERE]}

\section{First Breakpoint Test Results}

The variance/covariance break point test outlined in $\S(3)$ is used to detect the first breakpoint in the models after January 1, 2007. Table A.7 presents the list of breakpoints. The first key feature of the results for this test is that there are little discernable patterns across countries or in fact maturities for the first detected breakpoint. It should be noted that breakpoints are detected in every country over the sample, which would be expected as the global credit market moved in a period of crisis post August 2007.

A number of interesting patterns can be seen in the results. For example, the majority of the first breakpoints appear to have occurred during 2008. In particular, in March 2008 as Bear Stearns became the first major financial firm to fall victim to the sub-prime mortgage and liquidity crisis. At this stage of the crisis, a general widening in both the credit and liquidity spreads occurs and this is an obvious feature of the plots in Figures A.1 A.8. An interesting point to note is that the several countries have relatively stable profiles post 2007. The model for the 10-year Portuguese sovereign debt, for instance, only has a significant break point in March 2010.

A key facet of Table A.7 is that the use of the time varying coefficients model is strongly justified, relative to the time invariant set-up of for instance, Longstaff et al. (2005).

\section{[TABLE A.7 GOES ABOUT HERE OR TOP OF NEAREST PAGE TO HERE]}

\section{$T V-V A R$ Roots}

The time varying roots of the slope coefficient matrix $\tilde{B}_{t}$ for four indicative models are presented in Figures A.9 to A.12. Several caveats are in order in the interpretation of the roots. In a standard static coefficients set-up the value of the largest root is indicative of the fundamental nature of the vector stochastic process. For instance, roots inside the unit circle indicate a covariance stationary process (i.e. there is a long run mean value). Roots equal to one suggest the presence of at least one random walk in the vector process and as such the vector process is non-stationary. Roots greater than one suggest an explosive process which approaches infinity at a rate faster than a unit root process, see Hamilton (1994) for discussion.

In the context of substantial structural breaks in the slope coefficients of the VAR model, interpretation of the roots is less clear. A largest time varying root greater than one at time $t$ indicates that should the process continue with this matrix of slope coefficients then the vector process will explode and rapidly approach infinity.

Given the nature of the interventions by the ECB and the IMF in the Eurozone sovereign debt crisis, it would be expected that corrective actions would be implemented to prevent explosive roots causing such extreme discounting that par value the sovereign debt would effectively fall toward zero (i.e. infinite yield). 
In this sense a root above one for a given length of time indicates that the market has now completely priced in a substantial credit event as if it had already occurred.

Notably, in contrast to the largest root, if the smallest root is close to zero then there is rank deficiency in the slope coefficients matrix. This indicates that certain variables are now redundant (i.e. non stochastic functions of each other). A negative root (less than negative one) indicates that one or more of the equations have a sinusoidal component that cycle the system either to the stationary equilibrium or (if the largest root is one) back to the stochastic trend driven by the one or more random walks in the system.

Figure A.9 presents the evolution of the largest and smallest root for the slope coefficients for the 5-year model for Greece. The largest root is almost always above unity indicating the presence of an explosive trend. In particular, during the period from quarter 1, 2010 to quarter 2, 2010 the roots are substantially above one. From Figure A.1 and A.5 we can see that there is a sharp rise in the credit and liquidity spreads, corresponding to the persistent increase in the largest root. A similar pattern is observed for the 10-year model for Greece (Figure A.10) and for the 5- and 10-year models for Portugal, Figures A.11 and A.12. The key policy implication to remark here is that once the explosive roots are entrenched, a policy intervention is inevitable because the market will be unable to correct this explosive trend. The intensity of this process will inevitably be reinforced by the rapid growth in the CDS market, see the dashed line plot in Figure A.1 for instance.

\section{[A PANEL OF FIGURES A.9 TO A.12 GOES HERE]}

\section{TV-VAR Coefficients}

The final part of our analysis focuses on the evolution of the time varying coefficients for a selection of the models estimated in the study. We first use two case studies, Greece and Ireland to assess all four equations from the VAR system for the 5-year models. We then look at the bond credit spread equations (first equation from the TV-VAR model) for Portugal, France and Spain and compare both the 5- and 10 -year models. A snapshot of the average coefficients for the post first breakpoint periods can be found in Table A.8.

\section{[TABLE A.8 GOES HERE]}

\section{The Greek 5-Year Sovereign Bond Model}

Figures A.13 to A.16 present the time evolution of the four equations of the Greek 5-year model. Figures A.13 presents the coefficients for the first equation, the credit spread from the bond market as a function of the lags of itself, $\beta_{1,1, t}$, the lag of the credit spread from the CDS market, $\beta_{1,2, t}$, the lag of the liquidity spread of the bond market, $\beta_{1,3, t}$ and the lag of the liquidity spread of the CDS market, $\beta_{1,4, t}$.

The time evolution of $\beta_{1,1, t}$ illustrates the effectiveness of the RI-WLS in picking up the substantial and sudden changes in the coefficients over time, with periods of relative stability. For instance there is a gradual climb in the magnitude of $\beta_{1,1, t}$ from around 0.8 to 1 over 2007. In March 2008 as Bear Stearns is rescued the coefficient plummets to around 0.6-0.7. At this point the TV-VAR looses traction in explaining the yield, $\beta_{1,2, t}, \beta_{1,3, t}$ and $\beta_{1,4, t}$ are indistinguishable from zero. $\beta_{1,1, t}$ returns to a level just below unity before the end of 2008. The persistent explosive roots observed during 2010 are primarily as a consequence of the $\beta_{1,4, t}$ rising sharply from -0.4 to 0.4 and slightly less dramatic rise in $\beta_{1,3, t}$ from -0.2 to around 0.3 . This suggests that the liquidity of the CDS market is an important factor in explaining the explosive growth of the credit spreads for Greece.

Figure A.14 plots the time evolution of the coefficients for the second equation for the 5-year Greek model, the credit spread from the sovereign CDS market. Note the opposite pattern for the lagged coefficient on 
the credit spread from the sovereign bond market $\beta_{2,1, t}$. Our results clearly show a sharp rise around 2008 as the CDS market come under pressure following the demise of Bear Stearns, and banking credit spreads dispersed into the CDS markets, see Calice et al. (2011) for an analysis of this effect. The coefficient drops back to around 0.1 after the end of 2008 , but is still quite volatile. The primary driver in the CDS equation is its own lag, $\beta_{2,2, t}$, and the lag of its own liquidity spread, $\beta_{2,4, t}$, other than for a short period during early 2007.

Figure A.15 plots the time varying coefficients for the third equation of the Greek 5-year model, the liquidity spread on the bond market, as function of the lags of the itself and the other variables. $\beta_{3,1, t}$ is the coefficient on the lag of the credit spread of the bond market. After March 2008 this coefficient rises substantially then falls just after quarter 3 of the same year. The lag of the credit spread of the CDS market is found to be effectively insignificant for the entire sample period, except for a short period again between March 2008 and the start of 2009, when it was marginally positive. The coefficient on the lag value of the liquidity spread of the bond market $\beta_{3,3, t}$ is quite high with an average of around 0.6, see also Table A.8, panel (d). The most striking feature is the changing impact of the lag of the liquidity spread in the CDS market $\beta_{3,4, t}$. The coefficient violently changes, from between 1.5 and 2.5 over the whole of the 2008-2009 period. As the explosive roots appear in late 2010, the coefficient settles to zero.

This is an economically important finding for policy makers. The liquidity and depth of the sovereign credit markets are indeed critically important for the smooth and efficient functioning of international money markets. The evidence here suggests that the sovereign CDS market can have a substantial impact on the liquidity and transaction costs of the the sovereign debt market. Furthermore, it is important to note that this effect can appear and vanish in a rapid manner. Thus, this compelling evidence seems to lend support to the illiquidity spillover hypothesis, i.e. that illiquidity in financial markets is contagious, see for instance Tang and Yan (2006).

The time evolution plots of the coefficients for the final equation of the 5-year Greek model are presented A.16. This is the liquidity spread from the sovereign CDS market as a function of the other lagged variables in the system. In a similar pattern to the liquidity spread for the sovereign bond market, the liquidity spread on the sovereign CDS market is unaffected for most of the sample by the lags of the credit spreads on the sovereign bond and CDS markets, $\beta_{4,1, t}$ and $\beta_{4,2, t}$. However, at the end of the sample during 2010, suddenly these coefficients grow in magnitude substantially, $\beta_{4,1, t}$ rises from 0 to 0.6 and then settles to 0.2 by the end of the sample. Similarly the $\beta_{4,2, t}$ rises from 0 to around 0.35 during the middle of 2010 . This is indicative of the explosive trend feeding back into the liquidity spread of the CDS market.

The key conclusion is that without external intervention in the Greek sovereign debt market (i.e. the imposition of another structural break, through the stability mechanism) the explosive trend will continue until credit spreads would rise further to a critical level that could ultimately trigger a default event. Notice also that recently writing haircuts on Greek sovereign debt have muted as being up to $40 \%$. It is reasonable to assume that an efficiently functioning, deep and liquid market cannot operate in presence of expected credit events of this magnitude. Furthermore, a reasonable question is 'has the sovereign CDS market destabilised the sovereign bond market?' The evidence of the model suggests that to some extent the speed of adjustment in the discounting on Greek sovereigns has been exacerbated by the presence of the sovereign CDS market and the transmission channel of this information is unambiguous. Once default is entrenched in expectations, the sovereign CDS market will inevitably cause the associated bond yield spreads to reach a level at which a bailout triggering the intervention of the relevant authorities (EU, ECB, IMF) would be inevitable. All in all, we believe that this is a reasonable interpretation of our results for Greece.

\section{[A SINGLE PANEL OF FIGURES A.13 to A.16 GOES HERE]}

\section{The Irish 5-Year Sovereign Bond Model}

Figures A.17 to A.20 present the time varying coefficients for the Irish 5-year sovereign debt model. 
The time evolution of the first equation of the model is presented in Figure A.17. The first and most salient feature of the plots is the similarity to the equivalent plots for the 5-year model for Greece. In particular, note the sudden changes that take place during 2008, after the Bear Stearns rescue. The coefficient weighting the evolution of the Irish bond market credit spreads as function of their lagged values, $\beta_{1,1, t}$, drops dramatically from a value of approximate unity at the beginning of March 2008 to around 0.35 prior to the beginning of 2009. Similarly, note that the plots for $\beta_{1,2, t}, \beta_{1,3, t}$ and $\beta_{1,4, t}$ have some clear parallels to the equivalent plots of the coefficients for the Greek 5 -year model, albeit with the Irish plot for $\beta_{1,4, t}$ having a less pronounced dip prior to the beginning of 2009.

We ascribe similar interpretations to the first equation of the Irish 5-year model in a similar fashion to the first equation within the Greek 5-year model. During the first quarter of 2008 the Bear Stearns rescue begins a sudden shift in the transmission coefficients for the sovereign debt market (similar breaks are observed for most Eurozone government bonds, 5- or 10-year maturities). This reduction in the lagged coefficient suggests the temporary presence of an unobserved component impacting the sovereign credit spreads. Over the period March 2008 - January 2009 none of the lagged series do exhibit explanatory power for the variation in the sovereign credit spreads.

The plots of the coefficients for the second equation in the Irish 5-year model are presented in Figure A.18. Again we notice for the Irish 5-year model a pattern that resembles that of the Greek 5-year model. However, the transmission from the liquidity spread of the bond market plays a significant role in explaining the CDS credit spread during 2008. We note also that during periods of severe market distress the coefficient on the lagged values of the liquidity spreads rises substantially. This then translates into a common-liquidity related impact on the sovereign credit spreads.

Figures A.18 and A.20 present the third and fourth equations for the 5-year Irish model. From these equations associated results, we can see a significant departure from the general patterns observed for the Greek 5-year model. $\beta_{3,3, t}$ is above 0.4 for the majority of the January 1, 2007 - October 1, 2010 period illustrated in the plots. However, for Ireland the coefficient starts at around 0.2 in January 2007 before rising to a peak of unity in late 2009. The key finding here is that the explosive trend for Ireland emerges in the latter period of our sample under examination. This finding differs from the specific dynamics of Greece. In addition the switch from a stationary to non-stationary system in the liquidity spreads on the bond market is always near unity for Greece (i.e. the coefficient is close to being higher than unity for a longer period of time). This is a remarkable finding since this suggests that Greece had been far more vulnerable to shifts in $\beta_{3,3, t}$ than Ireland.

We believe that the evolution of $\beta_{3,3, t}$ is important and a fundamental driving factor. As this coefficient rises the liquidity spread on the bond market becomes more persistent. When the coefficient reaches unity, shocks to the liquidity of the bond market are aggregated in time and the liquidity spread process becomes non-stationary. When $\beta_{3,3, t}$ increases above unity, then an explosive trend emerges and public intervention is required as the sovereign credit market would be unable to restablish stable long-run equilibrium conditions. In fact, it is impossible for the market to return to equilibrium once the explosive trend has taken hold as the yield will be pushed explosively towards zero. No rational market response could force participants to trade against the explosive trend.

The equation driving the evolution of the liquidity spread on the CDS market for Irish debt is somewhat more mundane than the Greek CDS liquidity spread. $\beta_{4,4, t}$ only spikes above untidy briefly in late 2010 as the Irish debt crisis grew to an unsustainable point. At this point the explosive trend in liquidity effect occurs and forces the intervention and bailout. Again the evidence suggests that the CDS market would not be able to find a stable equilibrium if no intervention (and hence break point) would have occurred.

\section{[A SINGLE PANEL OF FIGURES A.17 to A.20 GOES HERE]}

\section{5- and 10-Year Credit Spread Models}

Figures A.21 to ?? present the coefficients of the first equation for the 5- and 10-year models for Portugal, Spain and France. The first interesting observation to note here is that the difference in the time evolution 
of $\beta_{1,1, t}$ for the 5- and 10-year models. For the 5-year models there is a noticeable and sudden drop in the coefficients for the March 2008 to October 2008 period. However, the 10-year models (other than for a brief period at the start of 2007 for Spain) remain stable, at just below unity.

\section{[A SINGLE PANEL OF FIGURES A.21 to ?? GOES HERE]}

Our results also suggest that the coefficient on the lag of the liquidity spread for the CDS market is at points highly important in determining the credit spread in the bond market. This implied a substantial lagged transmission effect between the liquidity spreads of the CDS market and the credit spreads for the bond market. However, when coupled with the knowledge that the positions that might be taken in the CDS market require no up front cost (other than the cost of collateral) the existence of this information channel implies a substantial frailty in sovereign debt markets during crisis.

The fact that roots in the liquidity spread for the CDS market can increase, persistently, above unity (implying an explosive trend) and the non-zero transmission of information to the credit spread in the bond market is a critical observation that is impossible to ignore. This effect is observed at the daily frequency (i.e. it is not a microstructure based limit to arbitrage scenario) and with a degree of persistence that can last for months.

What are the implications for policymaking? This is a relatively simple question to answer given the previous interpretation of the roots and coefficients. Take Greece for instance. What is the correct spread for bailout repayments on a debt instrument taking a proportion of Greek 5-year goverment bonds out of the market? We can clearly observe from the VAR analysis results an explosive trend occurring at the beginning of 2009. In addition, we see, from the first equation, abrupt oscillations in the impact of the CDS liquidity spread, see Figure A.13. Therefore, market data from post January, 2010 should should be carefully interpreted. As of December 2009, the Greek credit spread for both the bond and CDS market jumped to around 300 basis points, the last point at which the market appears to be operating normally. A natural conclusion would be to charge 300 basis points above German debt for any future restructuring. Linear interpolation between the 5- and 10-year models allows computation of spreads on intermediate maturity Greek sovereign debt instruments.

\section{Conclusions}

We have outlined a an empirical model of cross liquidity and price discovery in parallel markets using a time varying vector autoregression. We have used this model to elucidate the impact of cross liquidity effects on the Eurozone sovereign debt and CDS spreads during the Eurozone sovereign debt crisis.

We document three noteworthy findings. First, we show that explosive trends did appear during the sovereign crisis and that the CDS market does appear to have been a driver in most cases. Second, we find a positive and significant lagged transmission from the liquidity spread of the CDS market (proxied by the bid-ask spread) to the credit spread in the bond market. Finally, we observe several variance breaks in the time varying models indicating that the noise structure inundating the VAR model has changed markedly over the 2007-2010 period.

These findings indicate that: a) static models would be uninformative and indeed biased when estimated over such a dataset and b) that the information structure of the sovereign credit market has undergone substantial and dramatic adjustments throughout the crisis period.

The implications of our results for policy makers and practitioners is significant. For instance, it is clear that, in the absence of a coordinated EU action, the explosive trend would have resulted in a complete market failure for the trade sovereign debt instruments for several Eurozone countries. The time evolution of the coefficients plots point to a multitude of structural breaks in the slope coefficients, illustrating the difficulty that the band market participants have faced in correctly pricing these instruments. For instance, time invariant VAR models would not be an appropriate choice for asset pricing in this context, nor would standard factor models of the yield curve. 
Future research should focus on an analysis of potential spillover effects between countries, rather than simply the CDS versus the bond market for individual countries. We believe that the commonality in the time evolution of the coefficients for the various countries in the sample points towards this type of contagion effect.

\section{References}

Acharya, V. and R. Engle (2009). Anatomy of trading and liquidity in the credit defaults swaps market. Technical report, NYU Stern School of Business.

Acharya, V. and L. H. Pedersen (2005). Asset pricing with liquidity risk. Journal of Financial Economics 77(2), 375-410.

Amihud, Y. and H. Mendelson (1991). A noisy rational expectations equilibrium for multi-asset securities markets. Econometrica $46(4), 1141-1425$.

Arvastson, L., H. Olsson, and J. Holst (2000). Asymptotic bias in parameter estimation of ar-processes using recursive least squares with exponential forgetting. Scandinavian Journal of Statistics 27(1), 177-192.

Bongaerts, D., F. De Jong, and J. Driessen (2011). Derivative pricing with liquidity risk: Theory and evidence from the credit default swap market. The Journal of Finance 66(1), 203-240.

Buhler, W. and M. Trapp (2009). Time-varying credit risk and liquidity premia in bond and CDS markets. Technical Report 09-13, Centre for Financial Research (CFR) working paper.

Bystrom, H. N. E. (2005). Credit default swaps and equity prices: The iTraxx CDs index market. Technical Report 2005:24, Lund University working paper.

Calice, G., J. Chen, and J. Williams (2011). Are there benefits to being naked? the returns and diversification impact of capital structure arbitrage. European Journal of Finance, Forthcoming.

Chen, J., J. Williams, and R. Buckland (2011). A tale of two market microstructures: Spillovers of informed trading and liqudity for cross listed Chinese A and B shares. Article ID1755567, University of Aberdeen, Working Paper/SSRN.

Chen, L., D. Lesmond, and J. Wei (2007). Corporate yield spreads and bond liquidity. The Journal of Finance 62(1), 119-149.

Chordia, T., R. Roll, and A. Subrahmanyam (2001). Market liquidity and trading activity. The Journal of Finance 56(2), pp. 501-530.

Chordia, T., R. Roll, and A. Subrahmanyam (2008). Liquidity and market efficiency. Journal of Financial Economics 87(2), 249-268.

Chordia, T., A. Sarkar, and A. Subrahmanyam (2003). An empirical analysis of stock and bond market liquidity. Staff Reports 164, Federal Reserve Bank of New York.

De Jong, F. and J. Driessen (2007). Liquidity risk premia in corporate bond markets. Technical report, University of Amsterdam.

Diebold, F. X. and R. S. Mariano (1995). Comparing predictive accuracy. Journal of Business and Economic Statistics 13(3), 253-263.

Ericsson, J. and O. Renault (2002). Liquidity and credit risk. The Journal of Finance 61(5), 2219-2250.

Giacomini, R. and B. Rossi (2010). Forecast comparisons in unstable environments. Journal of Applied Econometrics 25(4), 595-620.

Hamilton, J. D. (1994). Time Series Analysis. Princeton University Press.

Han, S. and H. Zhou (2007). Nondefault bond spread and market trading liquidity. Technical report.

Jacoby, G., G. J. Jiang, and G. Theocharides (2009). Cross-market liquidity schocks: Evidence from CDS, corporate bond, and equity markets. Technical report, working paper.

Longstaff, F. A., S. Mithal, and E. Neis (2005). Corporate yield spreads: default risk or liquidity? new evidence from credit-default swap market. The Journal of Finance 60(5), 2213-2253.

Mahanti, S., A. Nashikkar, and M. Subrahmanyam (2008). Latent liquidity and corporate bond yield spreads. Technical Report FIN-06-023, New York University working paper.

Muirhead, R. J. (1981). Aspects of Multivariate Statistical Theory. John Wiley \& Sons, New Jersey.

Norden, L. and M. Weber (2004). The co-movement of credit default swap, bond and stock markets: an empirical analysis. European Financial Management 15(3), 529-562.

Roll, R. (1984). A simple implicit measure of the effective bid-ask spread in an efficient market. Journal of Finance 39(4), $1127-39$.

Tang, D. Y. and H. Yan (2006). Liquidity, liquidity spillover, and credit default swap spreads. Technical report, Kennesaw State University and University of South Carolina.

Wang, Y. (2009). Liquidity effects on corporate bond spreads. Technical report, The Penn State University.

Williams, J. (2011). How predictable are equity covariance matrices?: Evidence from high frequency data for four markets. Article, University of Aberdeen, Working Paper/SSRN.

Zhu, H. (2006). An empirical comparison of credit spreads between the bond market and the credit default swap market. Journal of Financial Services Research 29(2), 211-235. 


\section{Appendix A. Tables and Figures}

The tables and figures are contained in this section. An internet appendix with the full catalogue of models is also provided online. 
Table A.1: Time line of events during the Eurozone debt crisis.

\begin{tabular}{|c|c|}
\hline Date & Event \\
\hline August 2007 & $\begin{array}{l}\text { BNP Paribas liquidates two funds heavily in- } \\
\text { vested in mortgage back securities, subprime cri- } \\
\text { sis effectively begins. }\end{array}$ \\
\hline March 2008 & $\begin{array}{l}\text { Bear Stearns bought by JP Morgan with support } \\
\text { from US Federal Reserve. }\end{array}$ \\
\hline August 2008 & $\begin{array}{l}\text { Lehman Brothers enters Chapter } 11 \text { bankruptcy, } \\
\text { global financial panic begins. }\end{array}$ \\
\hline October 2008 & $\begin{array}{l}\text { Icelandic banking system nationalised, UK assets } \\
\text { seized under anti-terrorism laws. }\end{array}$ \\
\hline January/February 2009 & $\begin{array}{l}\text { Icelandic government collapses, first sovereign } \\
\text { victim, Iceland applies to join European Union } \\
(\mathrm{EU}) \text {. }\end{array}$ \\
\hline November 2009 & $\begin{array}{l}\text { Greek government revises public sector deficit to } \\
12.7 \% \text { GDP from } 6 \% \text { originally stated. }\end{array}$ \\
\hline December 2009 & Greek credit rating cut by Fitch from A- to BBB. \\
\hline April 2010 & $\begin{array}{l}\text { Greece applies for help from the EU and the In- } \\
\text { ternational Monetary Fund (IMF). }\end{array}$ \\
\hline May 2010 & $\begin{array}{l}\text { European Financial Stability Facility (EFSF) is } \\
\text { set up with Euros } 440 \text { Billion. }\end{array}$ \\
\hline September 2010 & $\begin{array}{l}\text { Ireland announces it will need Euros } 46 \text { Billion to } \\
\text { bailout its crippled financial sector. }\end{array}$ \\
\hline October 2010 & $\begin{array}{l}\text { End of CDS data provision by CMA for our sam- } \\
\text { ple. }\end{array}$ \\
\hline April 2011 & Portugal files for support from EFSF and IMF. \\
\hline May 2011 & $\begin{array}{l}\text { Predicted total public debt for Greece, Ireland } \\
\text { and Portugal forecast to be } 166.1 \%, 117.9 \% \text { and } \\
107.4 \% \text { of GDP respectively. }\end{array}$ \\
\hline
\end{tabular}




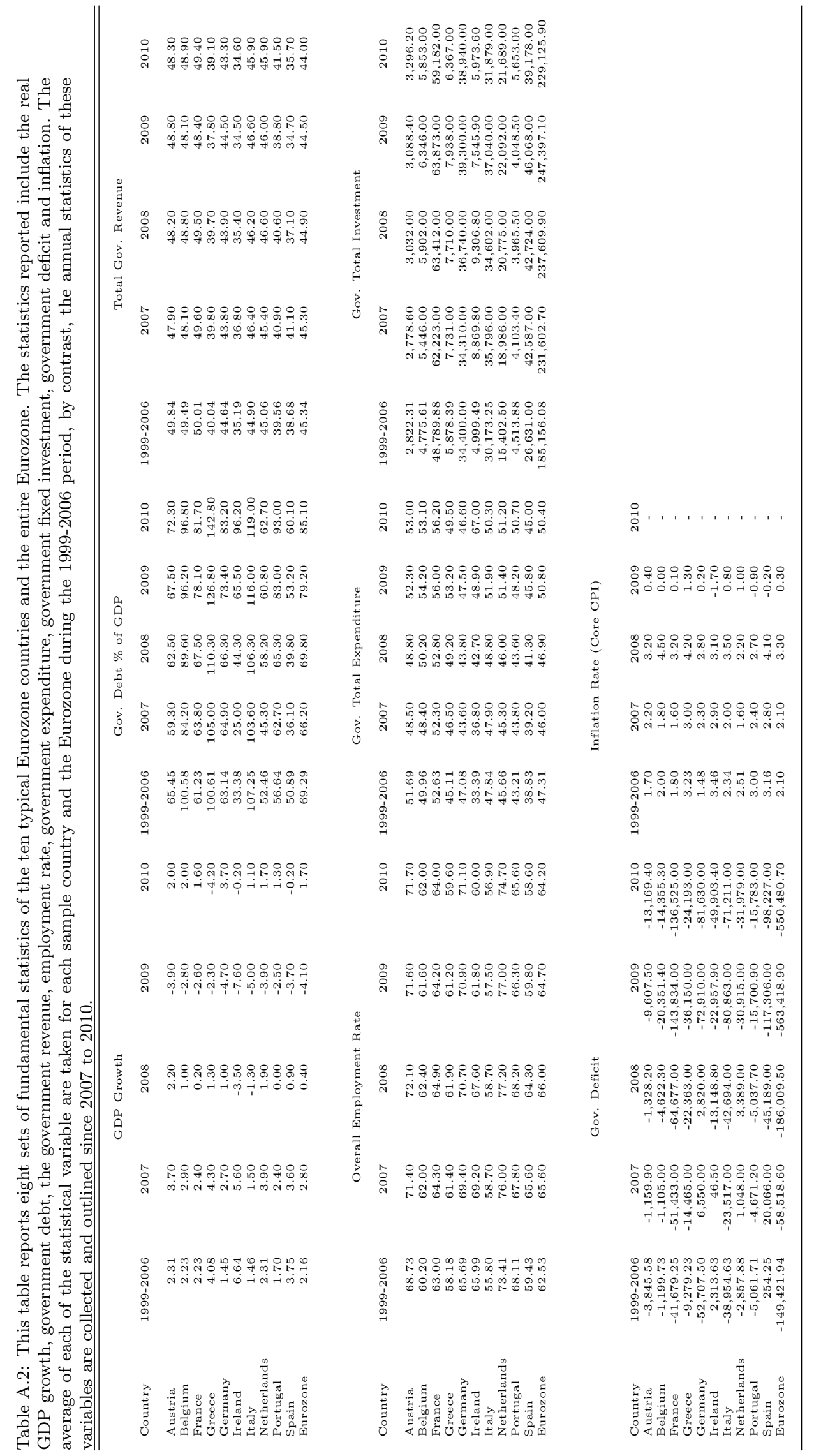


Table A.3: Reuters Information Codes. The 'Super' Reuters Information Codes are parent codes for a type of instrument. Each is set out with equals '=' sign at the end. For the CDS data, this corresponds to the source, e.g. MD denotes Markit. A blank provides the data from all available sources. In addition, CMA DataStream provides end of day aggregates spreads for CDSs on sovereign debt. Our 'macro' measure of the liquidity of the CDS market is an average of these sources.

\begin{tabular}{|c|c|c|c|c|c|c|c|}
\hline Name & Short Name & \multicolumn{2}{|c|}{ BOND RICs } & \multicolumn{4}{|c|}{ CDS RICs and DataStream/CMA Codes } \\
\hline AUSTRIA & AT & $\mathrm{AT} 5 \mathrm{YT}=$ & AT10YT= & ATGV5YUSAC $=$ & ATGV10YUSAC= & OEGVTS5 & OEGVTSX \\
\hline BELGIUM & $\mathrm{BE}$ & BE5YT= & $\mathrm{BE} 10 \mathrm{YT}=$ & BEGV5YUSAC $=$ & BEGV10YUSAC= & BGGVTS5 & BGGVTSX \\
\hline FRANCE & FR & FR5YT= & $\mathrm{FR} 10 \mathrm{YT}=$ & FRGV5YUSAC $=$ & FRGV10YUSAC $=$ & FRGVTS5 & FRGVTSX \\
\hline GERMANY & $\mathrm{DE}$ & DE5YT $=$ & $\mathrm{DE} 10 \mathrm{YT}=$ & DEGV5YUSAC= & DEGV10YUSAC $=$ & BDGVTS5 & BDGVTSX \\
\hline GREECE & GR & GR5YT $=$ & GR10YT $=$ & GRGV5YUSAC $=$ & GRGV10YUSAC $=$ & GRGVTS5 & GRGVTSX \\
\hline IRELAND & IE & $\mathrm{IE} 5 \mathrm{YT}=$ & IE10YT= & IEGV5YUSAC= & IEGV10YUSAC= & IRGVTS5 & IRGVTSX \\
\hline ITALY & IT & $\mathrm{IT} 5 \mathrm{YT}=$ & $\mathrm{IT} 10 \mathrm{YT}=$ & ITGV5YUSAC $=$ & ITGV10YUSAC $=$ & ITGVTS5 & ITGVTSX \\
\hline NETHERLANDS & NL & NL5YT $=$ & NL10YT $=$ & NLGV5YUSAC $=$ & NLGV10YUSAC $=$ & NLGVTS5 & NLGVTSX \\
\hline PORTUGAL & PT & $\mathrm{PT} 5 \mathrm{YT}=$ & $\mathrm{PT} 10 \mathrm{YT}=$ & PTGV5YUSAC= & PTGV10YUSAC $=$ & PTGVTS5 & PTGVTSX \\
\hline SPAIN & ES & $\mathrm{ES} 5 \mathrm{YT}=$ & $\mathrm{ES} 10 \mathrm{YT}=$ & ESGV5YUSAC= & ESGV10YUSAC = & ESGVTS5 & ESGVTSX \\
\hline
\end{tabular}

Table A.4: Tick History CDS, OTC Source: Thomson-Reuters Tick History Data Service. As a decentralised and global market, the CDS spread bid, spread asked (offered) and spread transacted data are aggregated daily from OTC transactions and recorded by the following sources. At present we do not have access to the entire transaction history for the CDS market. As a result, we do not know the total daily numbers of informative ticks for the CDS sources.

\begin{tabular}{ll}
\hline \hline ABN AMRO & ANZ Investment Bank (Asia) \\
Barclays CDS NYC & Barclays Tokyo \\
BNP Paribas & Citigroup Global Mkts \\
Deutsche Bank NY & Deutsche Bank Singapore \\
DZ Bank, Frankfurt & GFI Market Recap \\
Handelsbanken & Hypovereinsbank \\
ICAP & ING Manila \\
J.P.Morgan & Mizuho Securities \\
Natexis & Nord LB, Hannover \\
RBS Japan & SEB \\
Standard Chartered Singapore & TIFFE \\
Tullett Prebon & UBS Japan \\
UBS Singapore & CMA \\
Markit & \\
\hline
\end{tabular}

Table A.5: Bond Data Information

The bond data is sourced from Thomson-Reuters. Ticks are the number of quotes and transactions (they are collected as a 3-tuple bid yield, ask yield and a corresponding nearest time after transaction yield) included in the dataset for each country. Zero yields reports the number of ticks which have been removed because one of the three data items is reported as a zero (in this case exactly equal to zero to 5 decimals, as during 2008 the yield on certain bonds declined towards zero). Corrupted ticks are the number of ticks removed because either the yield is not a number or the time stamp is incongruous with the surrounding time stamp or a negative bid ask spread. Rogue ticks are those quotes removed because they are $800 \%$ greater or smaller than the daily median quote using a logarithmic proportion. It is interesting to note the lack of informative ticks for Belgium and France. We are assured by the data vendor that all informative ticks have been utilised and comparison with a short Bloomberg sample of yield data does suggest that Belgium and France have indeed less informative updated ticks for the 2009-10 period. We ascribe this to the relatively benign state of the French and Belgium sovereign debt markets as the overall value of bonds transacted is, GDP adjusted, very similar (source Markit). Greece by contrast has a relatively low tick update frequency prior to 2009, but this significantly increases during the crisis period. Despite the low number of ticks for France and Belgium, this still averages nearly 1,000 updated ticks per day with matched bid, ask and transacted yields. Trading days refers to the matched trading days to the CDS data set, which runs August 15, 2005 to October 1, 2010.

\begin{tabular}{lrrrrr}
\hline \hline Country & Ticks & Zero Yields & Corrupted Ticks & Rogue Ticks & Trading Days \\
\hline Spain & $4,010,003$ & 606 & 0 & 24 & 1,339 \\
Austria & $5,609,129$ & 348 & 0 & 12 & 1,339 \\
Belgium & 978,395 & 55,981 & 0 & 0 & 1,339 \\
France & 708,122 & 31,168 & 0 & 2 & 1,339 \\
Germany & $2,141,828$ & 61 & 0 & 2 & 1,339 \\
Greece & $2,800,111$ & 18,574 & 0 & 4 & 1,339 \\
Ireland & $3,151,086$ & 4,982 & 0 & 6 & 1,339 \\
Italy & $3,800,255$ & 299,131 & 0 & 3 & 1,339 \\
Netherlands & $4,866,969$ & 593 & 0 & 4 & 1,339 \\
Portugal & $4,616,628$ & 10,253 & 0 & 3 & 1,339 \\
\hline
\end{tabular}


Table A.6: Descriptive Statistics

The arithmetic means of the various data series used in this study are presented below, standard deviations are presented in brackets. The table reads left to right where CS stands for credit spread and LS for liquidity spread all values are in basis points. Credit spreads are relative to the equivalent German benchmark bond. Therefore column one, row one presents the difference (in basis points) for Austrian five year nominal bond versus the equivalent five German bond. The whole sample in this case runs from January 1, 2000 to October 1, 2010. For each country we have also presented the post crisis spread for comparison, this runs from August 1, 2007 to October 1, 2010. Country short names and data statistics are presented in Table A.3.

\begin{tabular}{|c|c|c|c|c|c|c|c|c|}
\hline & \multicolumn{4}{|c|}{5 Year } & \multicolumn{4}{|c|}{10 Year } \\
\hline & Bond CS & CDS CS & Bond LS & CDS LS & Bond CS & CDS CS & Bond LS & CDS LS \\
\hline \multirow[t]{2}{*}{ AT whole } & 17.455 & 17.222 & 23.111 & 31.025 & 27.476 & 22.512 & 20.038 & 38.657 \\
\hline & [23.949] & {$[31.413]$} & {$[24.904]$} & [28.404] & {$[29.027]$} & {$[32.612]$} & {$[56.676]$} & [33.154] \\
\hline \multirow[t]{2}{*}{ AT 2007- } & 31.310 & 32.182 & 34.080 & 43.347 & 55.718 & 54.353 & 35.175 & 64.450 \\
\hline & {$[24.636]$} & {$[36.447]$} & [29.621] & [33.296] & {$[23.627]$} & [30.295] & [16.143] & [38.476] \\
\hline \multirow[t]{2}{*}{ BE whole } & 18.097 & 12.905 & 17.508 & 32.508 & 34.374 & 19.109 & 13.928 & 42.241 \\
\hline & {$[27.770]$} & [21.543] & [14.988] & [27.833] & {$[29.347]$} & [22.469] & [11.166] & [29.324] \\
\hline \multirow[t]{2}{*}{ BE 2007- } & 33.962 & 23.767 & 23.368 & 44.664 & 59.531 & 38.469 & 20.702 & 55.181 \\
\hline & [29.108] & {$[24.424]$} & {$[17.538]$} & [32.160] & [20.616] & [24.396] & [10.900] & [24.659] \\
\hline \multirow[t]{2}{*}{ FR whole } & 12.846 & 5.445 & 19.229 & 27.159 & 18.302 & 5.850 & 14.435 & 32.507 \\
\hline & [13.269] & [10.060] & {$[17.424]$} & [19.176] & {$[15.944]$} & [10.135] & [12.607] & [17.409] \\
\hline \multirow[t]{2}{*}{ FR 2007- } & 17.626 & 7.664 & 24.572 & 32.116 & 24.708 & 8.231 & 17.893 & 34.772 \\
\hline & [12.884] & [11.177] & [17.965] & [20.339] & [14.248] & [11.145] & [13.442] & [19.496] \\
\hline \multirow[t]{2}{*}{ GR whole } & 120.869 & 98.248 & 46.117 & 53.979 & 146.177 & 119.581 & 40.632 & 82.091 \\
\hline & {$[231.519]$} & [193.887] & [126.993] & [73.110] & [204.799] & {$[179.642]$} & {$[97.637]$} & [99.010] \\
\hline \multirow[t]{2}{*}{ GR 2007- } & 215.455 & 173.881 & 75.939 & 84.037 & 312.605 & 259.311 & 90.413 & 155.732 \\
\hline & {$[281.272]$} & [238.164] & [166.618] & [88.460] & [237.945] & [215.730] & [139.119] & {$[122.076]$} \\
\hline \multirow[t]{2}{*}{ IE whole } & 30.313 & 53.512 & 36.919 & 49.331 & 84.268 & 65.286 & 22.195 & 60.887 \\
\hline & [86.595] & {$[81.482]$} & {$[72.176]$} & {$[51.657]$} & {$[97.839]$} & [79.930] & {$[36.768]$} & [61.952] \\
\hline \multirow[t]{2}{*}{ IE 2007- } & 78.192 & 94.947 & 57.529 & 71.129 & 185.783 & 148.671 & 38.202 & 114.392 \\
\hline & {$[92.443]$} & [91.642] & {$[93.000]$} & {$[61.560]$} & [74.193] & {$[62.251]$} & [53.654] & [67.048] \\
\hline \multirow[t]{2}{*}{ IT whole } & 34.241 & 34.178 & 18.329 & 32.292 & 60.484 & 47.597 & 12.926 & 46.132 \\
\hline & [40.868] & [42.163] & {$[14.032]$} & [29.939] & {$[42.576]$} & {$[39.376]$} & {$[12.200]$} & {$[33.274]$} \\
\hline \multirow[t]{2}{*}{ IT 2007- } & 58.965 & 56.894 & 25.202 & 42.166 & 104.612 & 86.076 & 18.858 & 66.771 \\
\hline & {$[41.012]$} & {$[46.061]$} & {$[15.890]$} & {$[34.721]$} & {$[30.086]$} & {$[34.011]$} & [12.980] & {$[42.711]$} \\
\hline \multirow[t]{2}{*}{ NL whole } & 12.734 & 6.490 & 14.229 & 35.823 & 18.419 & 8.550 & 8.550 & 36.674 \\
\hline & [18.630] & {$[13.021]$} & {$[7.234]$} & [32.368] & {$[19.327]$} & {$[17.521]$} & [4.937] & [34.199] \\
\hline \multirow[t]{2}{*}{ NL 2007- } & 19.002 & 7.900 & 16.363 & 43.931 & 25.066 & 8.749 & 9.955 & 44.450 \\
\hline & [18.314] & {$[12.576]$} & {$[7.470]$} & [34.387] & [18.666] & [14.315] & [5.137] & [35.887] \\
\hline \multirow[t]{2}{*}{ PT whole } & 43.429 & 36.381 & 35.374 & 38.311 & 65.824 & 46.381 & 26.075 & 52.248 \\
\hline & {$[72.744]$} & {$[68.565]$} & [69.763] & {$[42.202]$} & {$[77.785]$} & [63.535] & [51.939] & [53.368] \\
\hline \multirow[t]{2}{*}{ PT 2007- } & 77.898 & 63.841 & 53.383 & 53.718 & 129.744 & 92.155 & 52.568 & 88.467 \\
\hline & [83.308] & [83.293] & [90.423] & {$[51.854]$} & {$[86.357]$} & [77.763] & [72.929] & {$[67.347]$} \\
\hline \multirow[t]{2}{*}{ ES whole } & 34.587 & 36.812 & 22.302 & 37.705 & 42.316 & 40.749 & 13.614 & 40.204 \\
\hline & [51.111] & [51.080] & {$[26.476]$} & [28.069] & {$[50.512]$} & {$[47.452]$} & {$[16.514]$} & {$[37.872]$} \\
\hline \multirow[t]{2}{*}{ ES 2007- } & 52.151 & 54.278 & 28.472 & 44.401 & 63.386 & 58.711 & 18.380 & 50.849 \\
\hline & {$[54.096]$} & {$[54.276]$} & {$[30.405]$} & [31.919] & {$[50.830]$} & {$[47.610]$} & [18.696] & [41.534] \\
\hline
\end{tabular}


Table A.7: Detected breakpoints post 2007

Break point identification is inherently difficult task and as such the results below should be treated as indicative, therefore we present the breaks in terms of break during month. We use a multivariate for of the variance breakdown test in the spirit of Giacomini and Rossi (2010) alternative approaches utilize the breaks in intercept approach of Hendry and Mizon (2002). In this case we compute the model covariances at each step from the block of residuals in using the estimates from Equation 11. These are then iteratively compared to the previous residual covariance matrix using the covariance equality test found in Equation 14. A structural break is detected when the computed test statistic exceeds a critical value $c_{\alpha}$, in this case a the $\alpha=95 \%$ cumulative density of a $\chi^{2}(\nu)$ where $\nu=\frac{1}{2} n(n+1)(1+m)$.

\begin{tabular}{|c|c|c|c|}
\hline \multicolumn{2}{|c|}{ Austria (AT) } & \multicolumn{2}{|c|}{ Belgium (BE) } \\
\hline 5 Year & 10 Year & 5 Year & 10 Year \\
\hline February 2008 & May 2007 & August 2007 & May 2008 \\
\hline \multicolumn{2}{|c|}{ France (FR) } & \multicolumn{2}{|c|}{ Greece (GR) } \\
\hline 5 Year & 10 Year & 5 Year & 10 Year \\
\hline March 2008 & January 2007 & January & January 2007 \\
\hline \multicolumn{2}{|c|}{ Ireland (IE) } & \multicolumn{2}{|c|}{ Italy (IT) } \\
\hline 5 Year & 10 Year & 5 Year & 10 Year \\
\hline May 2008 & September 2008 & March 2008 & November 2009 \\
\hline \multicolumn{2}{|c|}{ Netherlands (NL) } & \multicolumn{2}{|c|}{ Portugal (PT) } \\
\hline 5 Year & 10 Year & 5 Year & 10 Year \\
\hline March 2008 & January 2007 & February 2008 & March 2010 \\
\hline \multicolumn{4}{|c|}{ Spain (ES) } \\
\hline 5 Year & 10 Year & & \\
\hline March 2008 & August 2007 & & \\
\hline
\end{tabular}


Table A.8: VAR Average Coefficients and Standard Deviations

Averages of the daily time varying coefficients after the first detected structural break post August 1, 2007 period. Standard deviations of the coefficients are presented in brackets. The tables should be read as follows, $\beta_{j, i}$ is for the $j^{\text {th }}$ equation and the $i^{t h}$ variable slope coefficient. The order is bond credit spread, CDS credit spread, Bond liquidity spread and CDS liquidity spread.

(a) Austria (AT)

\begin{tabular}{rrrrr}
\hline \hline & $\beta_{j, 1}$ & $\beta_{j, 2}$ & $\beta_{j, 3}$ & $\beta_{j, 4}$ \\
\hline$\beta_{1, i}$ & 0.86705 & 0.03540 & 0.03734 & 0.04102 \\
& {$[0.13863]$} & {$[0.15116]$} & {$[0.07797]$} & {$[0.09067]$} \\
$\beta_{2, i}$ & 0.00346 & 0.84866 & 0.01025 & -0.00018 \\
& {$[0.03615]$} & {$[0.15261]$} & {$[0.02230]$} & {$[0.01855]$} \\
$\beta_{3, i}$ & 0.07201 & 0.15649 & 0.68136 & 0.09674 \\
& {$[0.14870]$} & {$[0.33411]$} & {$[0.19466]$} & {$[0.08540]$} \\
$\beta_{4, i}$ & 0.17968 & 0.06848 & 0.12858 & 0.71432 \\
& {$[0.20161]$} & {$[0.33383]$} & {$[0.23205]$} & {$[0.16119]$} \\
\hline
\end{tabular}

(c) France (FR)

\begin{tabular}{rrrrr}
\hline \hline & $\beta_{j, 1}$ & $\beta_{j, 2}$ & $\beta_{j, 3}$ & $\beta_{j, 4}$ \\
\hline$\beta_{1, i}$ & 0.75928 & 0.03384 & 0.04098 & 0.06770 \\
& {$[0.18401]$} & {$[0.26125]$} & {$[0.02859]$} & {$[0.11084]$} \\
$\beta_{2, i}$ & -0.01010 & 0.79011 & 0.00312 & 0.01227 \\
& {$[0.03361]$} & {$[0.15956]$} & {$[0.00624]$} & {$[0.01548]$} \\
$\beta_{3, i}$ & 0.40506 & 0.85787 & 0.47044 & 0.15440 \\
& {$[0.34842]$} & {$[1.34056]$} & {$[0.16742]$} & {$[0.16124]$} \\
$\beta_{4, i}$ & 0.31540 & 0.61431 & 0.11993 & 0.71599 \\
& {$[0.30183]$} & {$[0.84143]$} & {$[0.10467]$} & {$[0.11533]$} \\
\hline
\end{tabular}

(e) Ireland (IE)

\begin{tabular}{rrrrr}
\hline \hline & $\beta_{j, 1}$ & $\beta_{j, 2}$ & $\beta_{j, 3}$ & $\beta_{j, 4}$ \\
\hline$\beta_{1, i}$ & 0.84815 & 0.10336 & 0.00792 & 0.02718 \\
& {$[0.19323]$} & {$[0.17386]$} & {$[0.08639]$} & {$[0.06282]$} \\
$\beta_{2, i}$ & -0.01321 & 0.93282 & 0.03219 & 0.02220 \\
& {$[0.05706]$} & {$[0.11283]$} & {$[0.05864]$} & {$[0.02951]$} \\
$\beta_{3, i}$ & 0.01462 & 0.04410 & 0.59791 & 0.09977 \\
& {$[0.24669]$} & {$[0.21869]$} & {$[0.19807]$} & {$[0.13029]$} \\
$\beta_{4, i}$ & 0.06876 & 0.13967 & 0.25572 & 0.71616 \\
& {$[0.17054]$} & {$[0.28333]$} & {$[0.26062]$} & {$[0.11087]$} \\
\hline
\end{tabular}

(g) Netherlands (NL)

\begin{tabular}{rrrrr}
\hline \hline & $\beta_{j, 1}$ & $\beta_{j, 2}$ & $\beta_{j, 3}$ & $\beta_{j, 4}$ \\
\hline$\beta_{1, i}$ & 0.80906 & 0.05465 & 0.05164 & 0.03772 \\
& {$[0.22130]$} & {$[0.10286]$} & {$[0.10028]$} & {$[0.05761]$} \\
$\beta_{2, i}$ & 0.19732 & 0.77405 & 0.04959 & -0.01055 \\
& {$[0.58870]$} & {$[0.18535]$} & {$[0.11215]$} & {$[0.03068]$} \\
$\beta_{3, i}$ & 0.04862 & 0.03938 & 0.74842 & 0.08091 \\
& {$[0.12392]$} & {$[0.16775]$} & {$[0.16521]$} & {$[0.06868]$} \\
$\beta_{4, i}$ & 0.27691 & 0.18296 & 0.61845 & 0.65082 \\
& {$[0.41278]$} & {$[0.57948]$} & {$[0.50469]$} & {$[0.16112]$} \\
\hline
\end{tabular}

(b) Belgium (BE)

\begin{tabular}{rrrrr}
\hline \hline & $\beta_{j, 1}$ & $\beta_{j, 2}$ & $\beta_{j, 3}$ & $\beta_{j, 4}$ \\
\hline$\beta_{1, i}$ & 0.73517 & 0.14544 & 0.01931 & 0.08077 \\
& {$[0.20980]$} & {$[0.29340]$} & {$[0.08352]$} & {$[0.05505]$} \\
$\beta_{2, i}$ & 0.00562 & 0.90451 & 0.00924 & 0.00791 \\
& {$[0.03135]$} & {$[0.08737]$} & {$[0.01840]$} & {$[0.01588]$} \\
$\beta_{3, i}$ & 0.10656 & 0.08381 & 0.48137 & 0.09717 \\
& {$[0.09749]$} & {$[0.30758]$} & {$[0.29858]$} & {$[0.09045]$} \\
$\beta_{4, i}$ & 0.15860 & 0.23731 & 0.22692 & 0.66746 \\
& {$[0.16939]$} & {$[0.33145]$} & {$[0.23054]$} & {$[0.15923]$} \\
\hline
\end{tabular}

(d) Greece (GR)

\begin{tabular}{rrrrr}
\hline \hline & $\beta_{j, 1}$ & $\beta_{j, 2}$ & $\beta_{j, 3}$ & $\beta_{j, 4}$ \\
\hline$\beta_{1, i}$ & 0.88046 & 0.13451 & 0.06138 & 0.03247 \\
& {$[0.10958]$} & {$[0.09426]$} & {$[0.18639]$} & {$[0.11088]$} \\
$\beta_{2, i}$ & 0.01588 & 0.93759 & 0.02661 & 0.01685 \\
& {$[0.03218]$} & {$[0.10851]$} & {$[0.05887]$} & {$[0.09255]$} \\
$\beta_{3, i}$ & 0.05500 & -0.00281 & 0.69508 & 0.17948 \\
& {$[0.16930]$} & {$[0.18851]$} & {$[0.16767]$} & {$[0.39163]$} \\
$\beta_{4, i}$ & 0.08662 & 0.31466 & 0.13778 & 0.49978 \\
& {$[0.26162]$} & {$[0.39460]$} & {$[0.66210]$} & {$[0.18686]$} \\
\hline
\end{tabular}

(f) Italy (IT)

\begin{tabular}{rrrrr}
\hline \hline & $\beta_{j, 1}$ & $\beta_{j, 2}$ & $\beta_{j, 3}$ & $\beta_{j, 4}$ \\
\hline$\beta_{1, i}$ & 0.88739 & 0.12677 & 0.00243 & 0.00520 \\
& {$[0.12492]$} & {$[0.17167]$} & {$[0.07364]$} & {$[0.05386]$} \\
$\beta_{2, i}$ & 0.02129 & 0.94522 & 0.00623 & -0.00860 \\
& {$[0.03506]$} & {$[0.11114]$} & {$[0.04209]$} & {$[0.02701]$} \\
$\beta_{3, i}$ & 0.08177 & 0.15060 & 0.58398 & 0.02865 \\
& {$[0.15854]$} & {$[0.22506]$} & {$[0.16771]$} & {$[0.07468]$} \\
$\beta_{4, i}$ & 0.12184 & 0.26432 & 0.09982 & 0.50864 \\
& {$[0.23139]$} & {$[0.35908]$} & {$[0.23019]$} & {$[0.17881]$} \\
\hline
\end{tabular}

(h) Portugal (PT)

\begin{tabular}{rrrrr}
\hline \hline & $\beta_{j, 1}$ & $\beta_{j, 2}$ & $\beta_{j, 3}$ & $\beta_{j, 4}$ \\
\hline$\beta_{1, i}$ & 0.85964 & 0.14462 & -0.03579 & 0.03569 \\
& {$[0.14319]$} & {$[0.14025]$} & {$[0.08748]$} & {$[0.06480]$} \\
$\beta_{2, i}$ & -0.00268 & 0.95590 & 0.01478 & 0.00149 \\
& {$[0.07075]$} & {$[0.11942]$} & {$[0.03617]$} & {$[0.04648]$} \\
$\beta_{3, i}$ & 0.12393 & 0.03126 & 0.70276 & 0.11734 \\
& {$[0.18919]$} & {$[0.17803]$} & {$[0.14278]$} & {$[0.21101]$} \\
$\beta_{4, i}$ & 0.15885 & 0.37654 & 0.11297 & 0.56935 \\
& {$[0.17777]$} & {$[0.39561]$} & {$[0.25466]$} & {$[0.16610]$} \\
\hline
\end{tabular}

(i) Spain (ES)

\begin{tabular}{rrrrr}
\hline \hline & $\beta_{j, 1}$ & $\beta_{j, 2}$ & $\beta_{j, 3}$ & $\beta_{j, 4}$ \\
\hline$\beta_{1, i}$ & 0.84750 & 0.06941 & 0.04361 & 0.02797 \\
& {$[0.19066]$} & {$[0.07473]$} & {$[0.10836]$} & {$[0.07722]$} \\
$\beta_{2, i}$ & -0.00366 & 0.91803 & 0.02980 & -0.00413 \\
& {$[0.06738]$} & {$[0.14003]$} & {$[0.04913]$} & {$[0.02730]$} \\
$\beta_{3, i}$ & 0.09787 & 0.07691 & 0.55181 & 0.06830 \\
& {$[0.12524]$} & {$[0.13579]$} & {$[0.19701]$} & {$[0.10177]$} \\
$\beta_{4, i}$ & 0.42090 & 0.23362 & 0.47895 & 0.48549 \\
& {$[0.45238]$} & {$[0.22412]$} & {$[0.71193]$} & {$[0.19254]$} \\
\hline
\end{tabular}




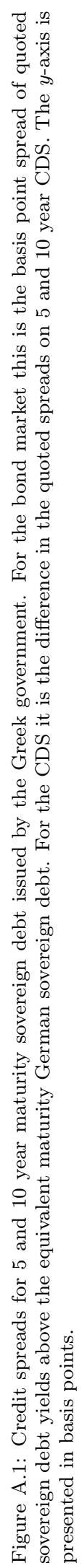
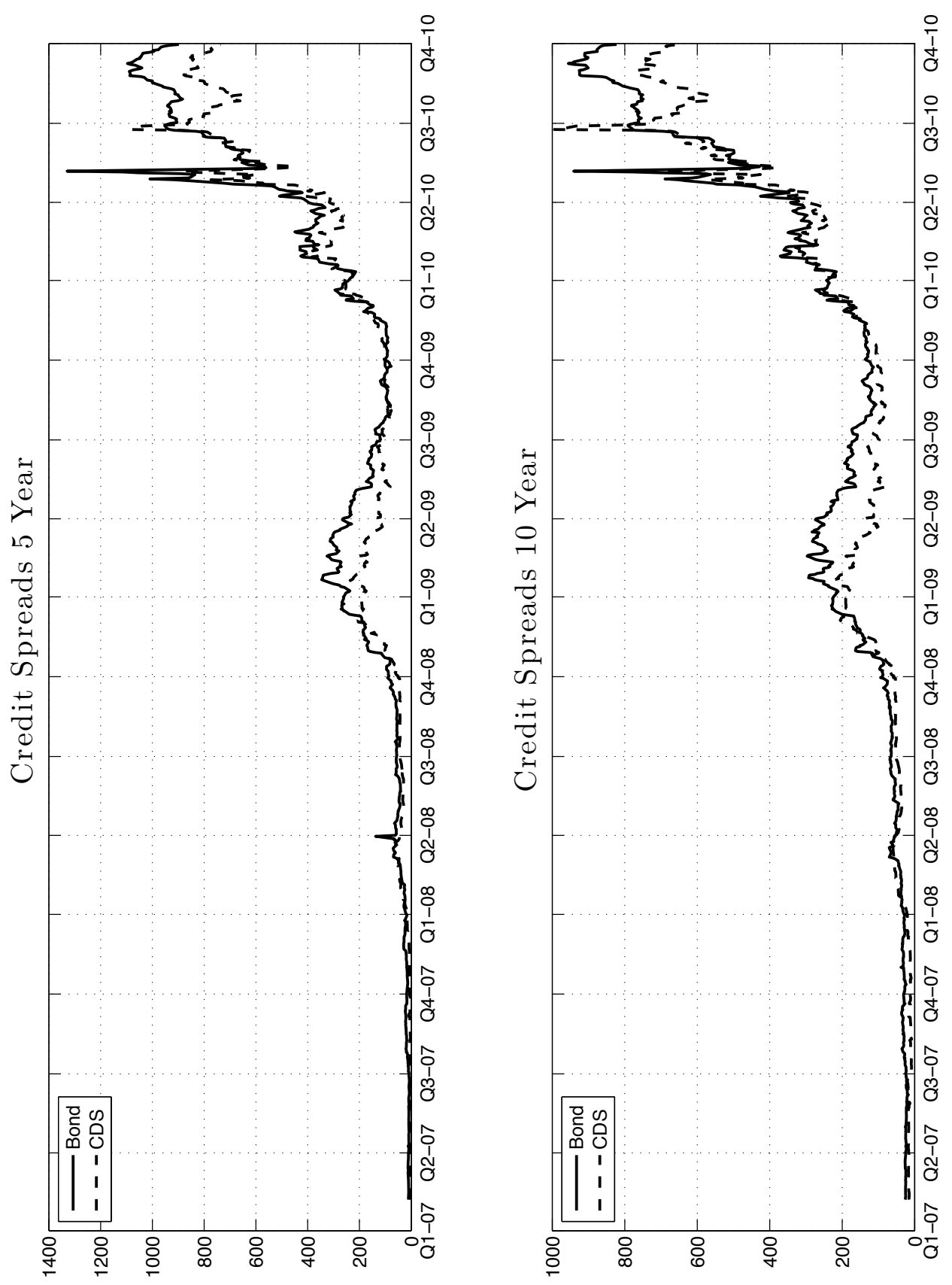

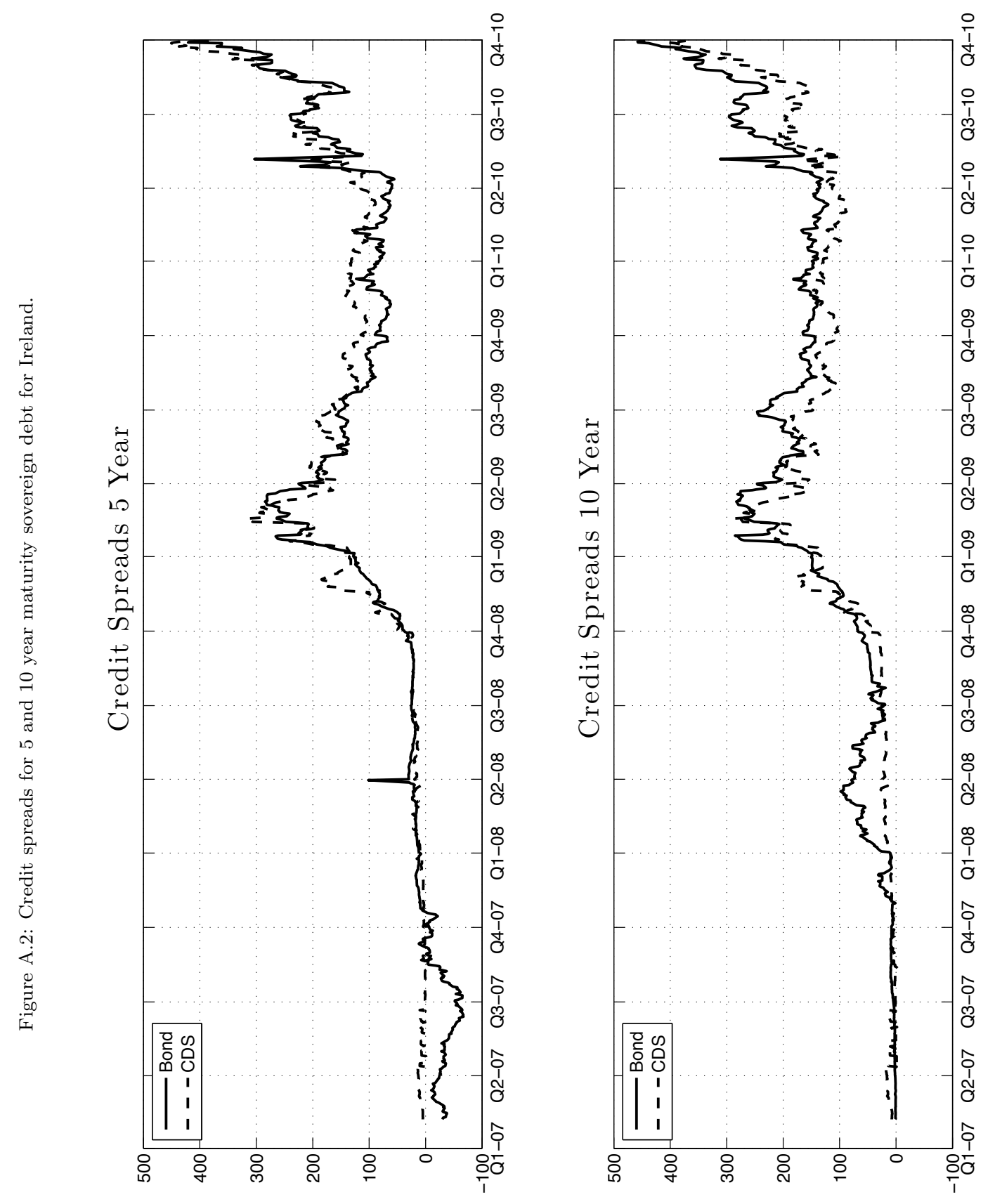

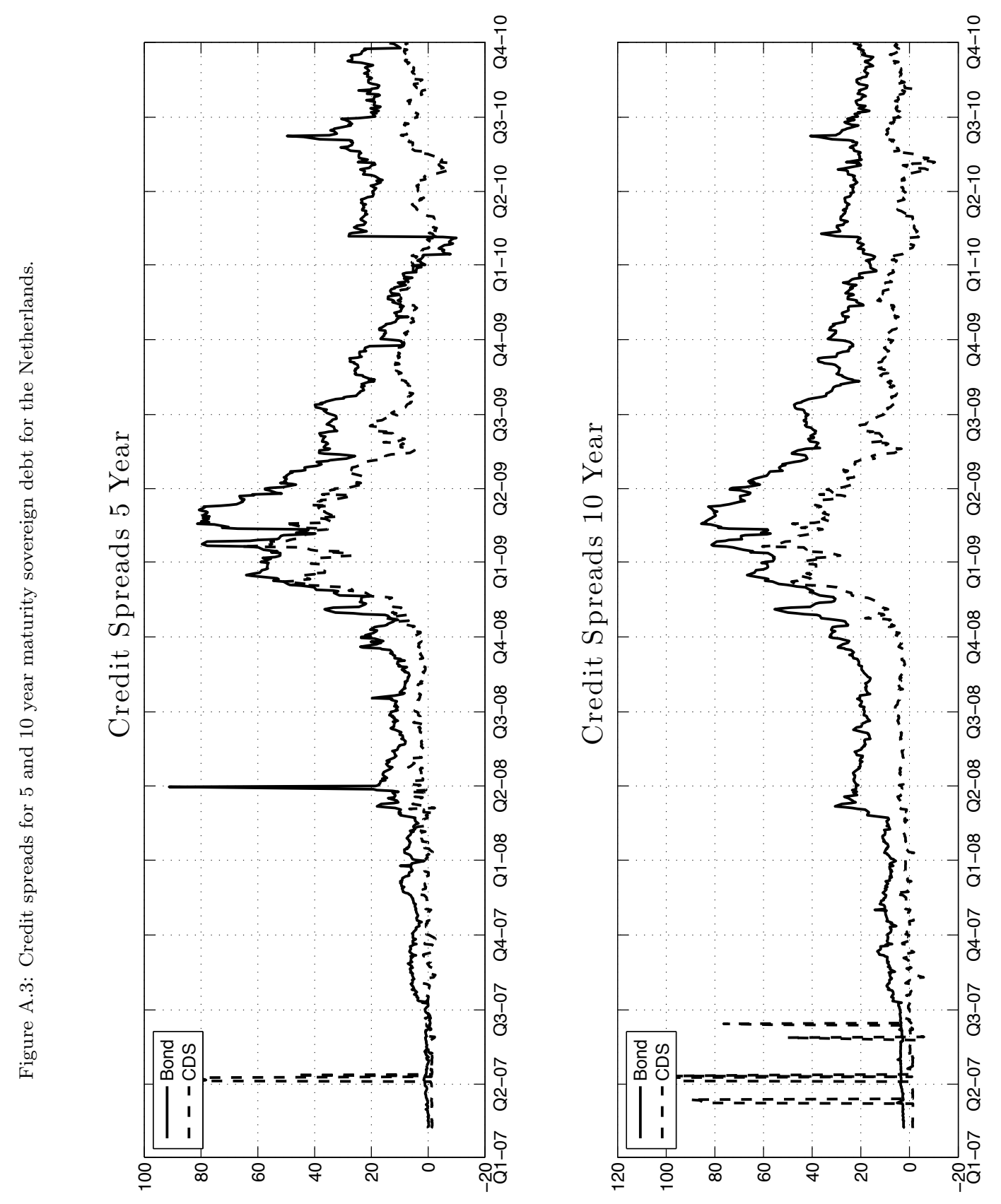

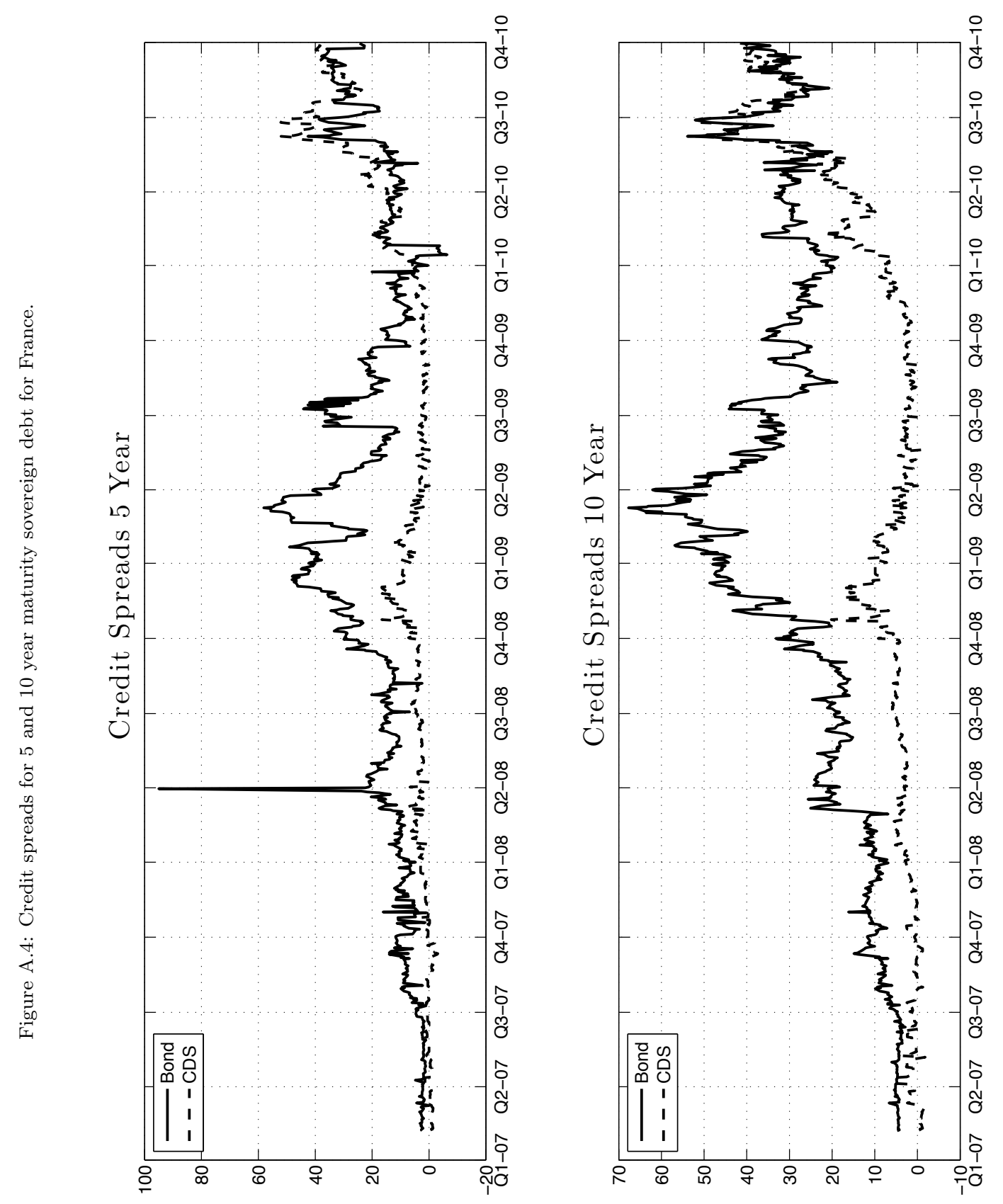


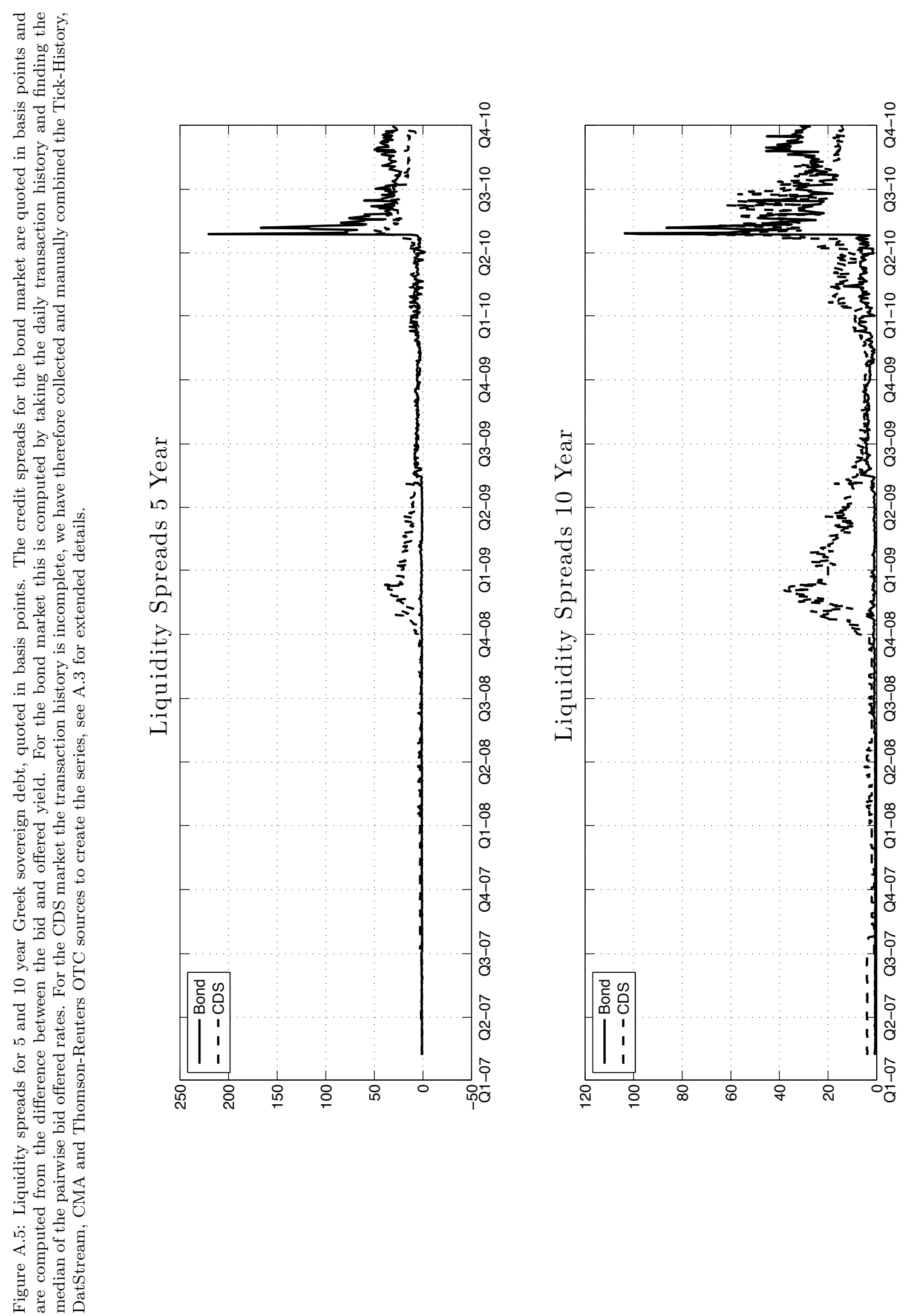



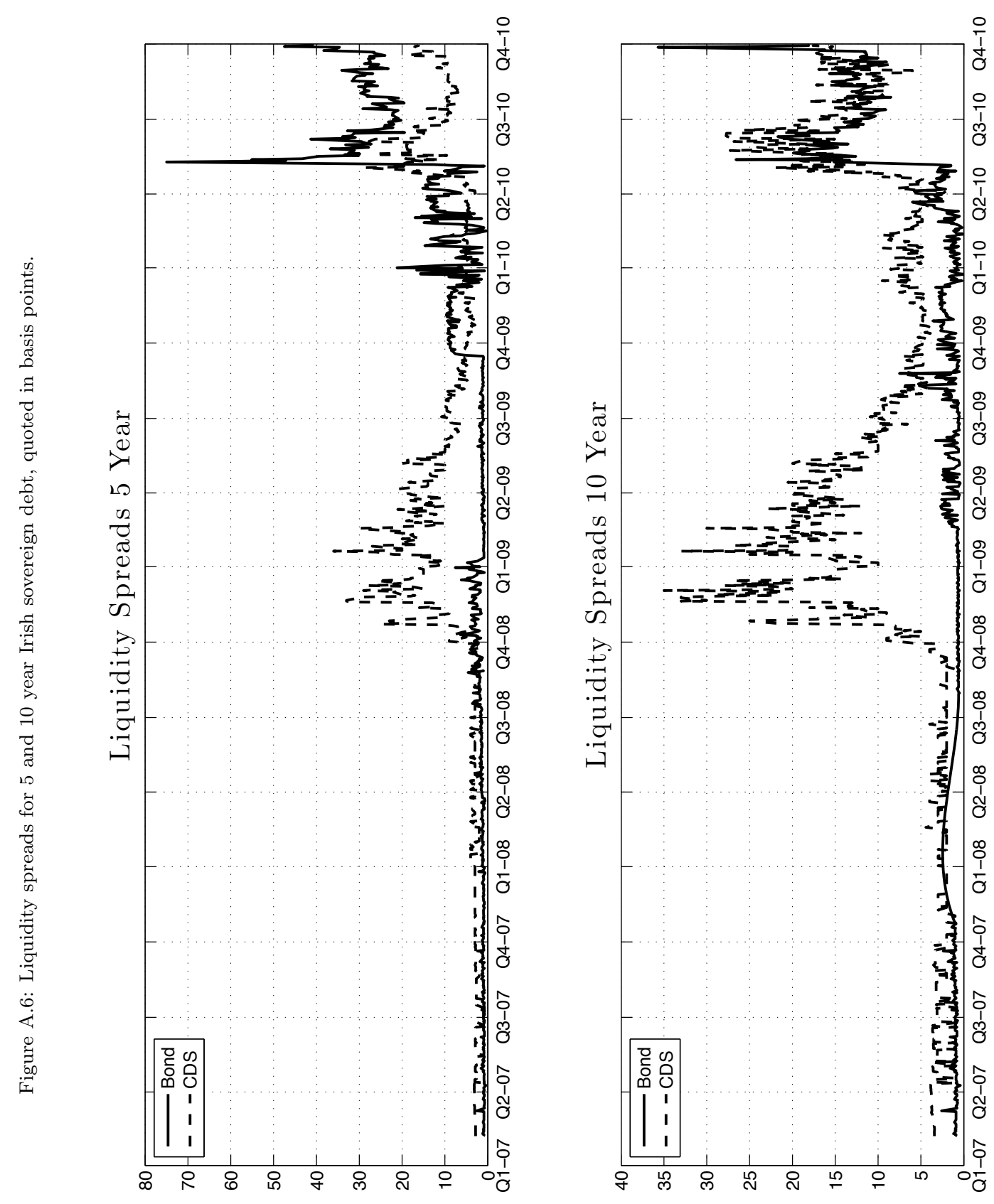


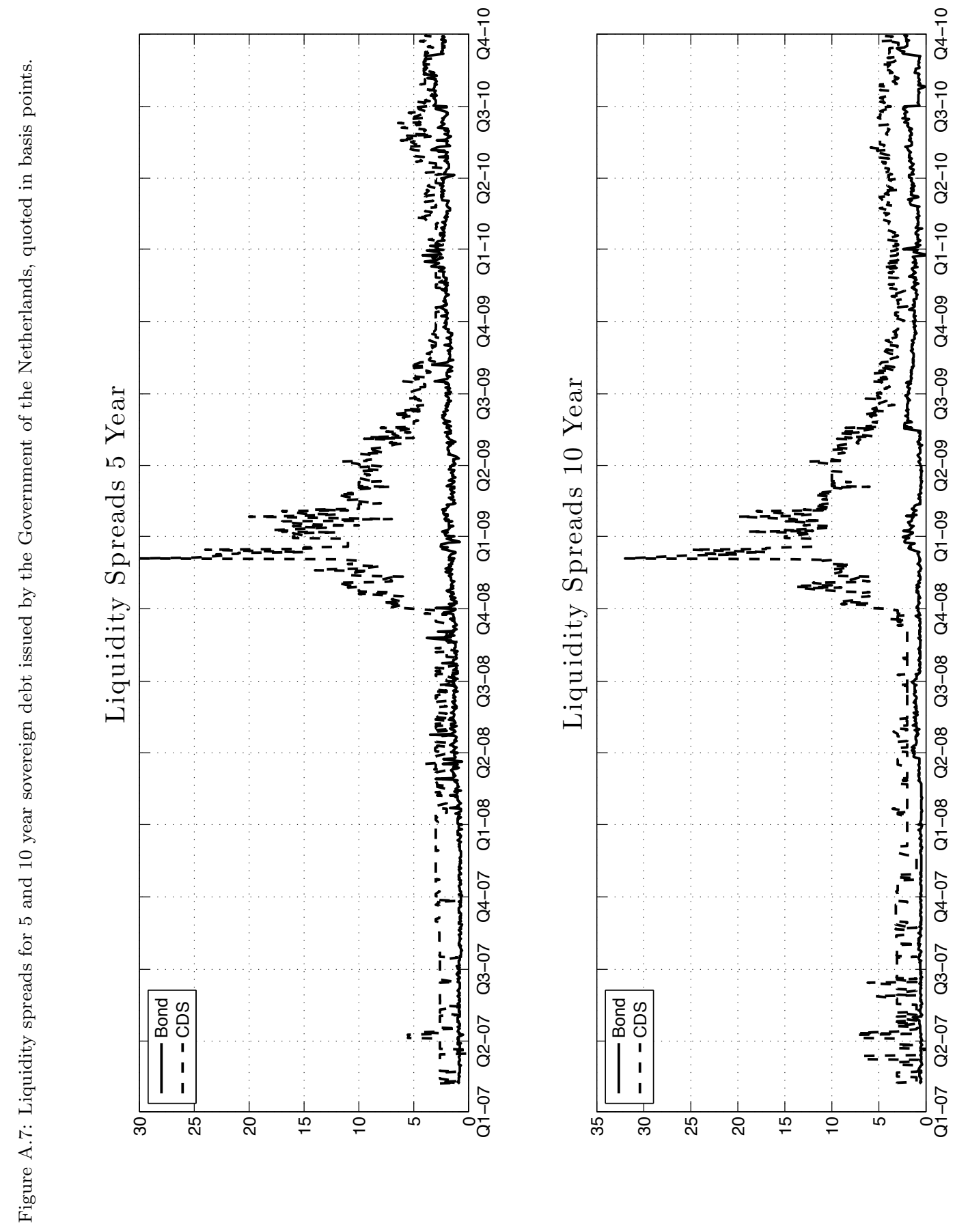



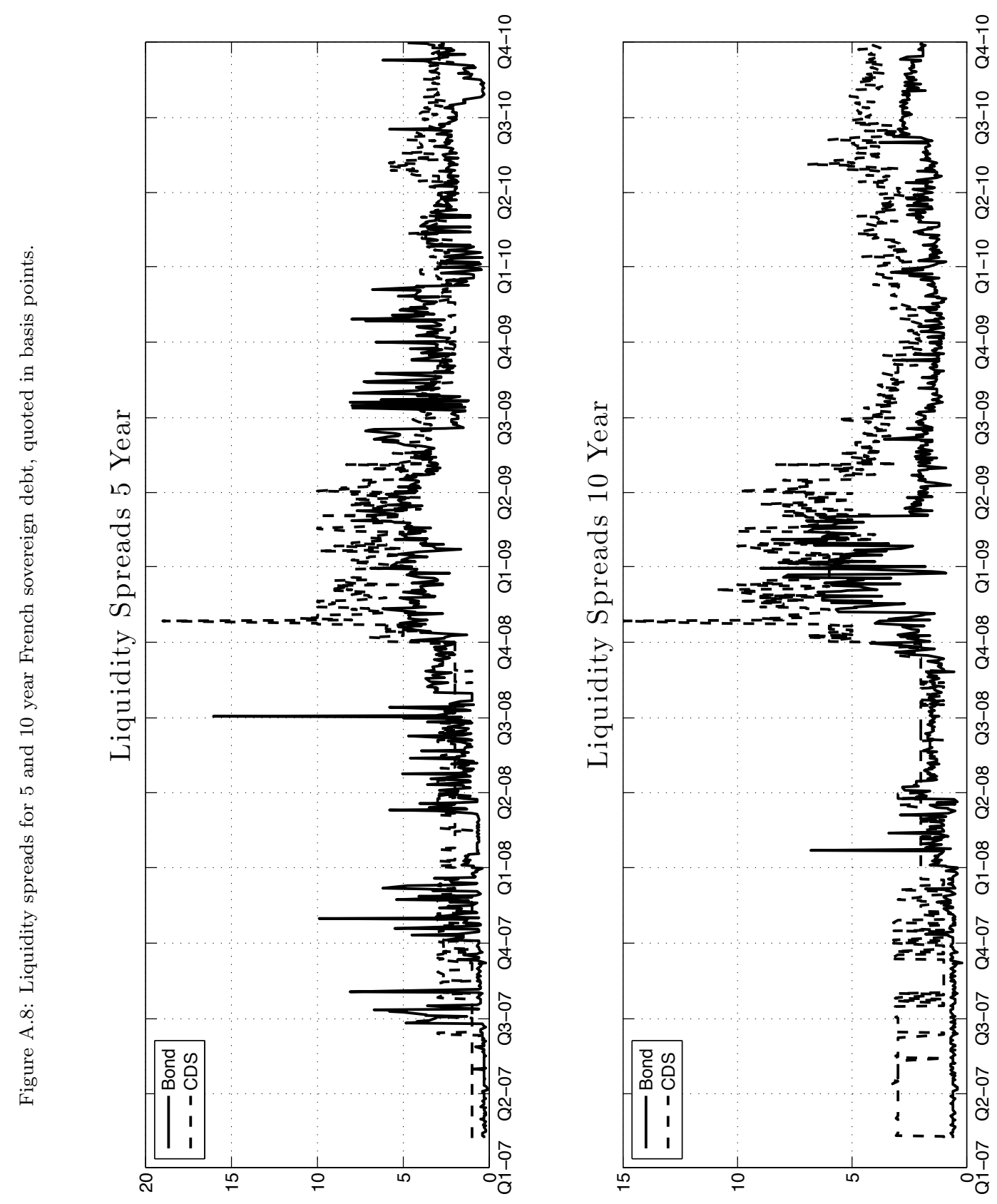


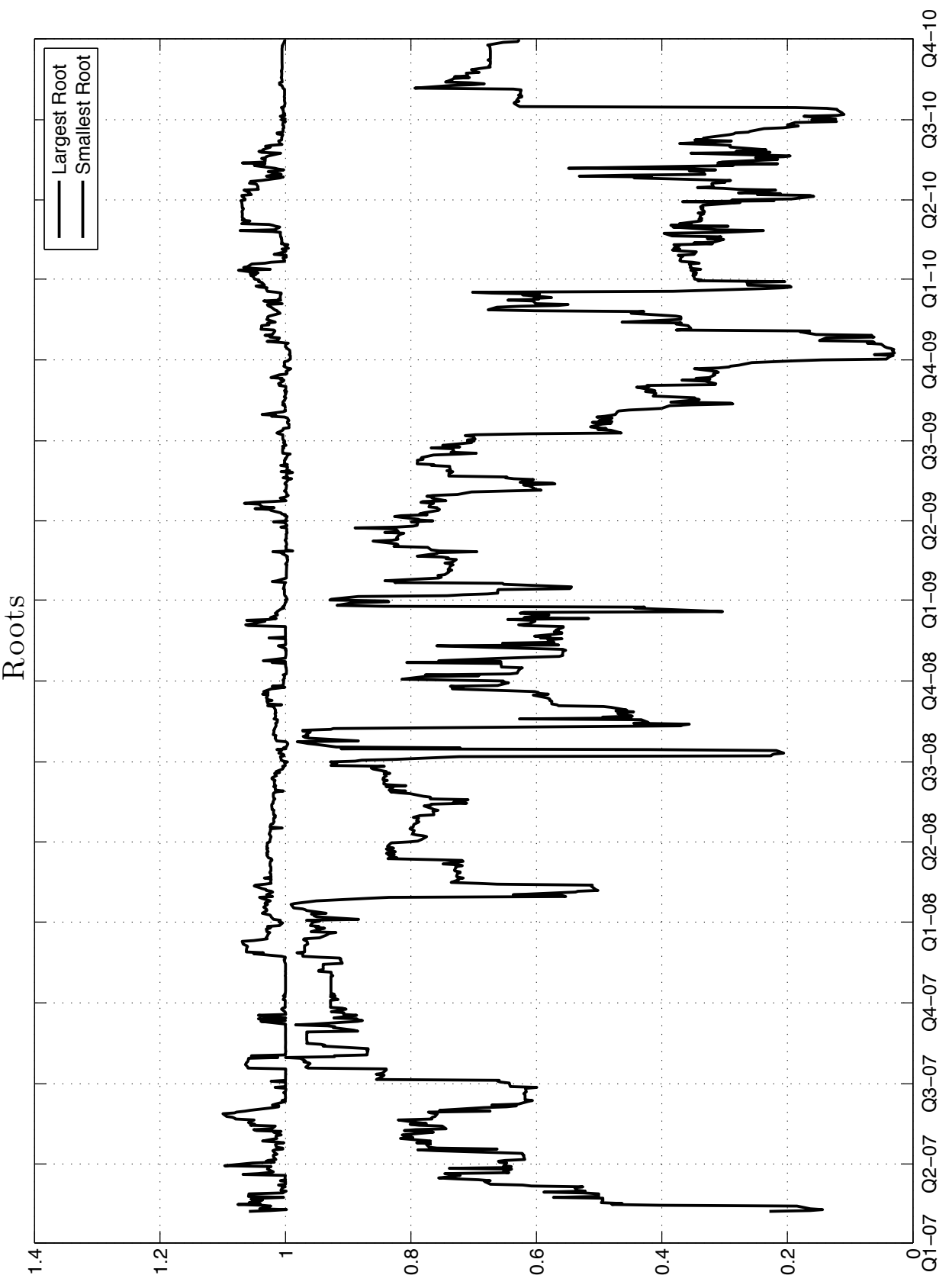




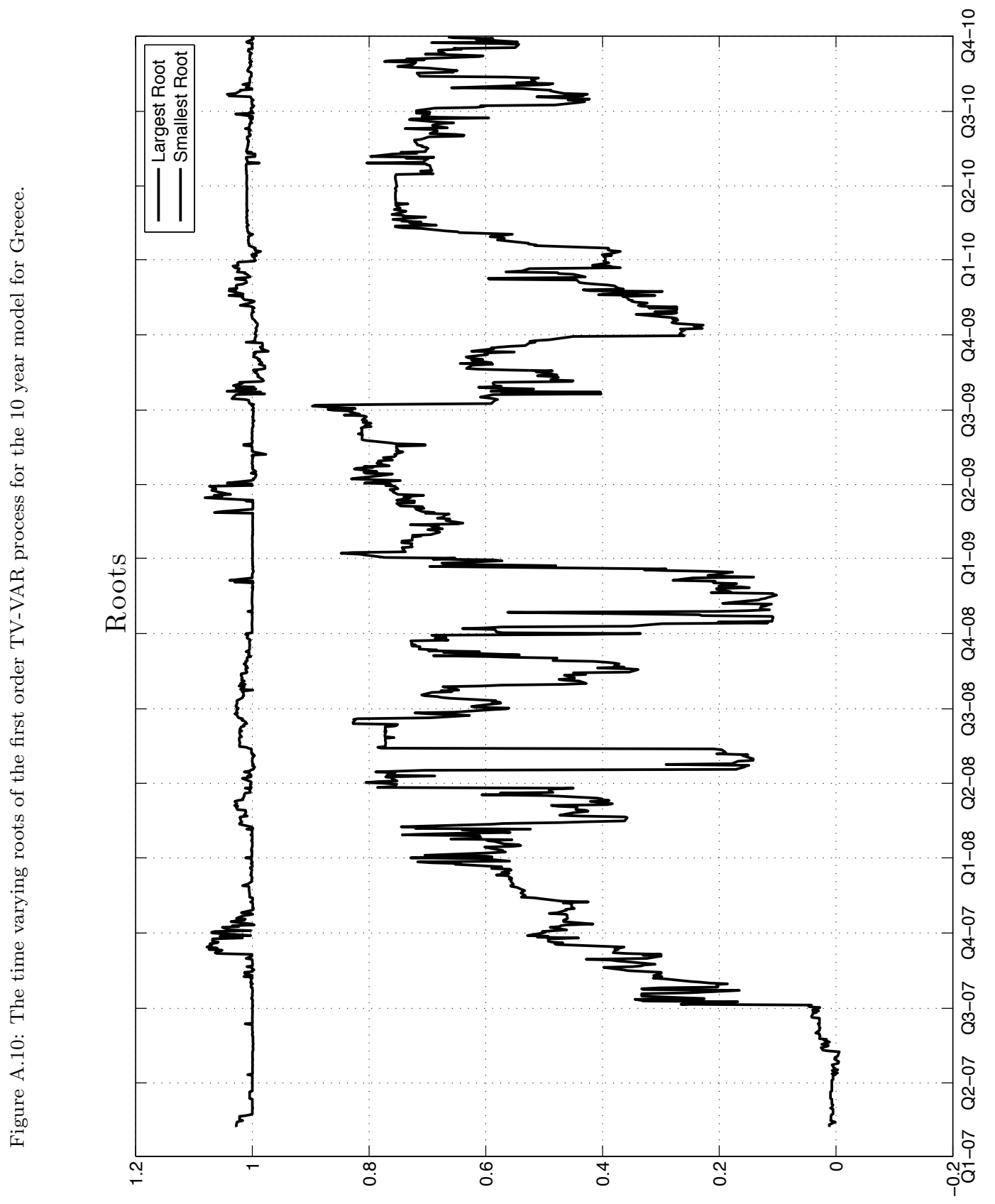




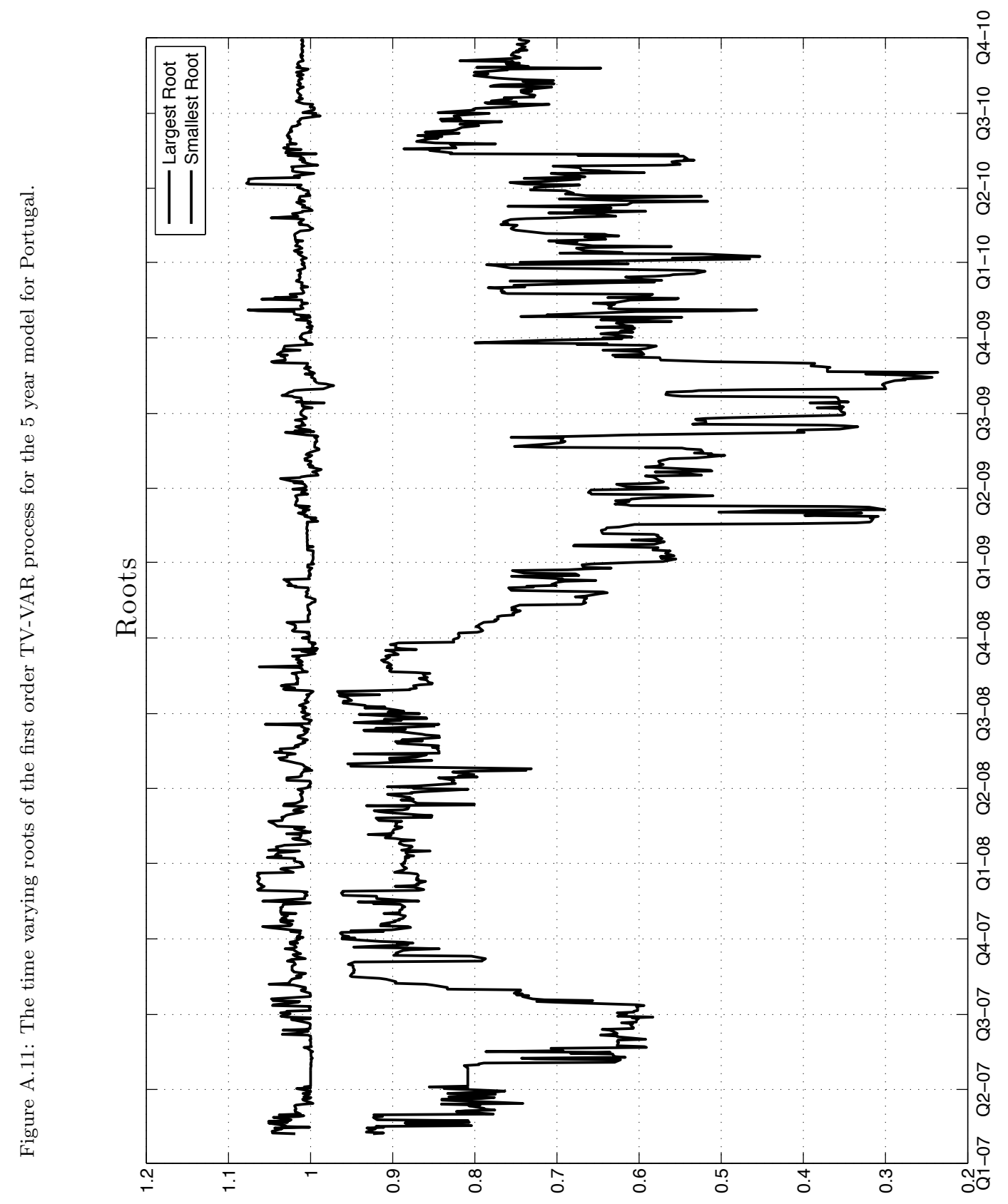




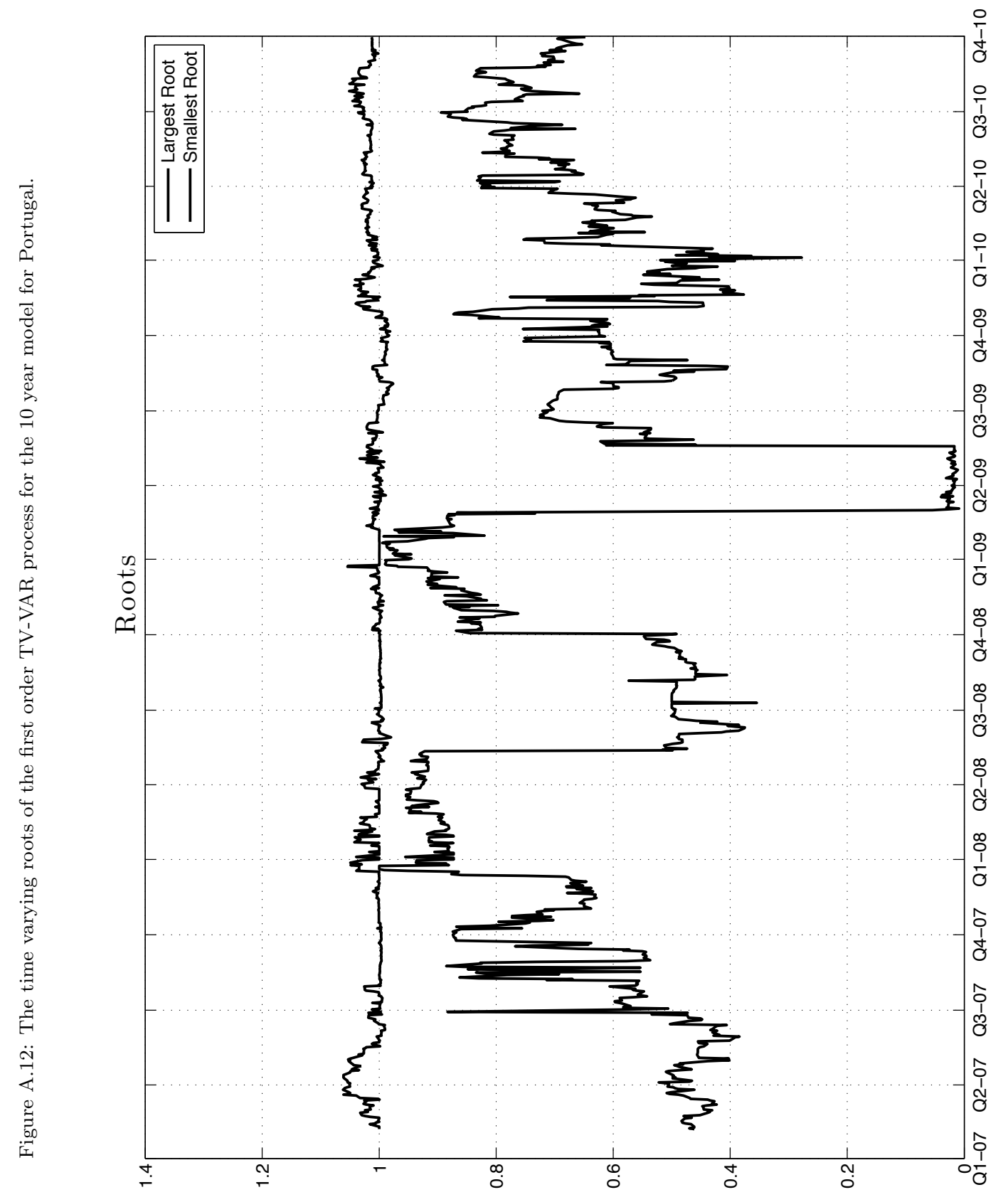



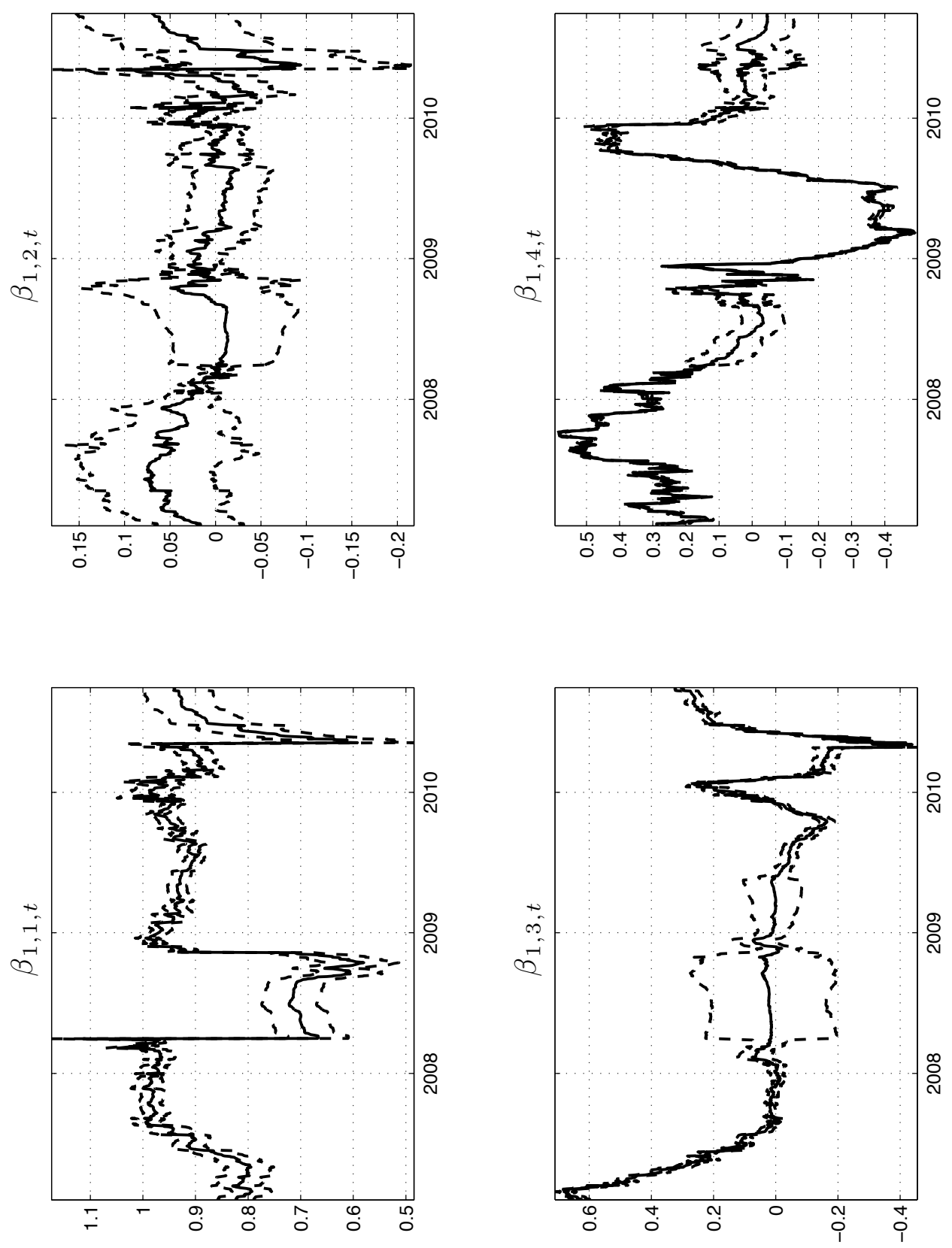

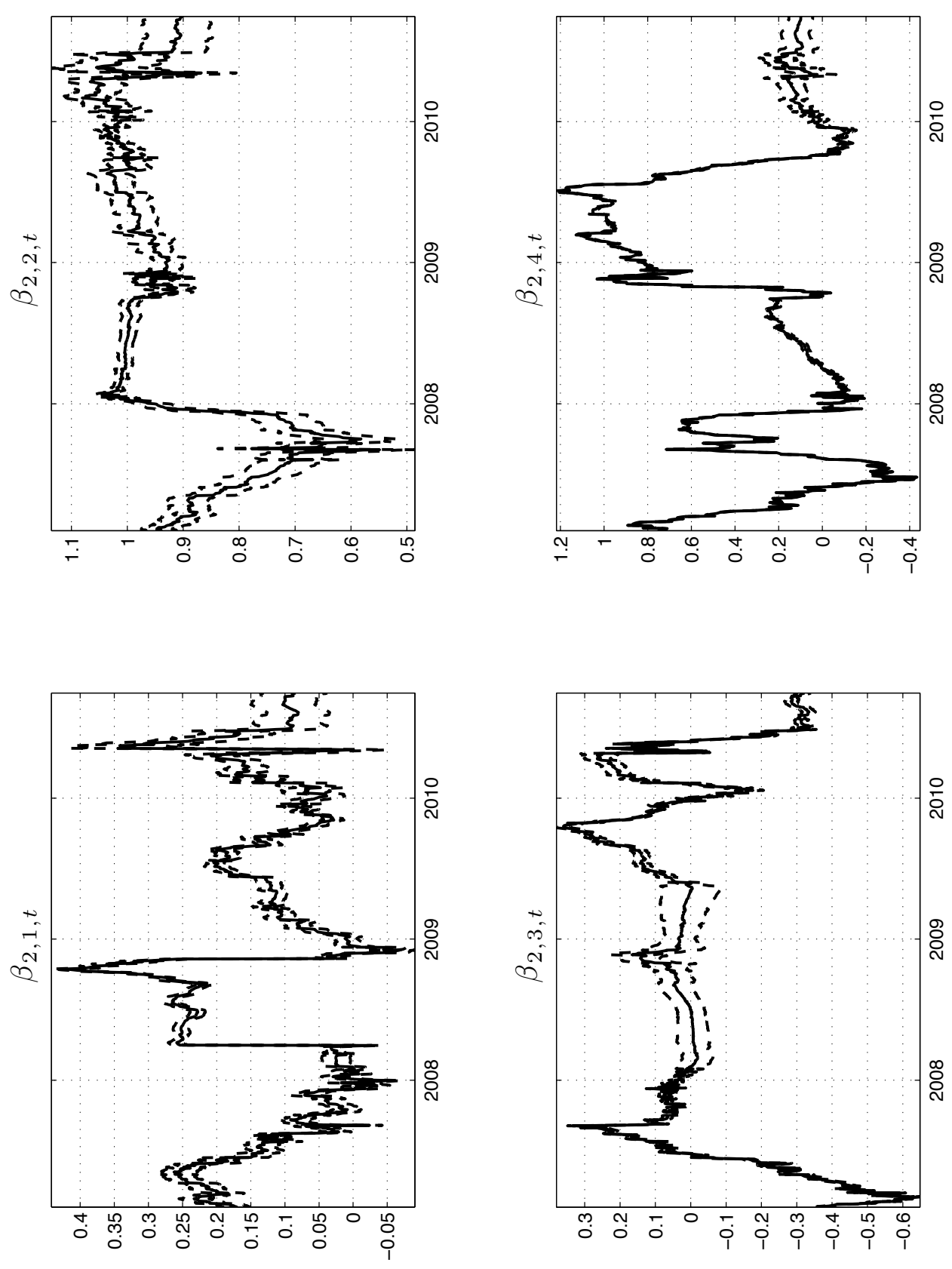

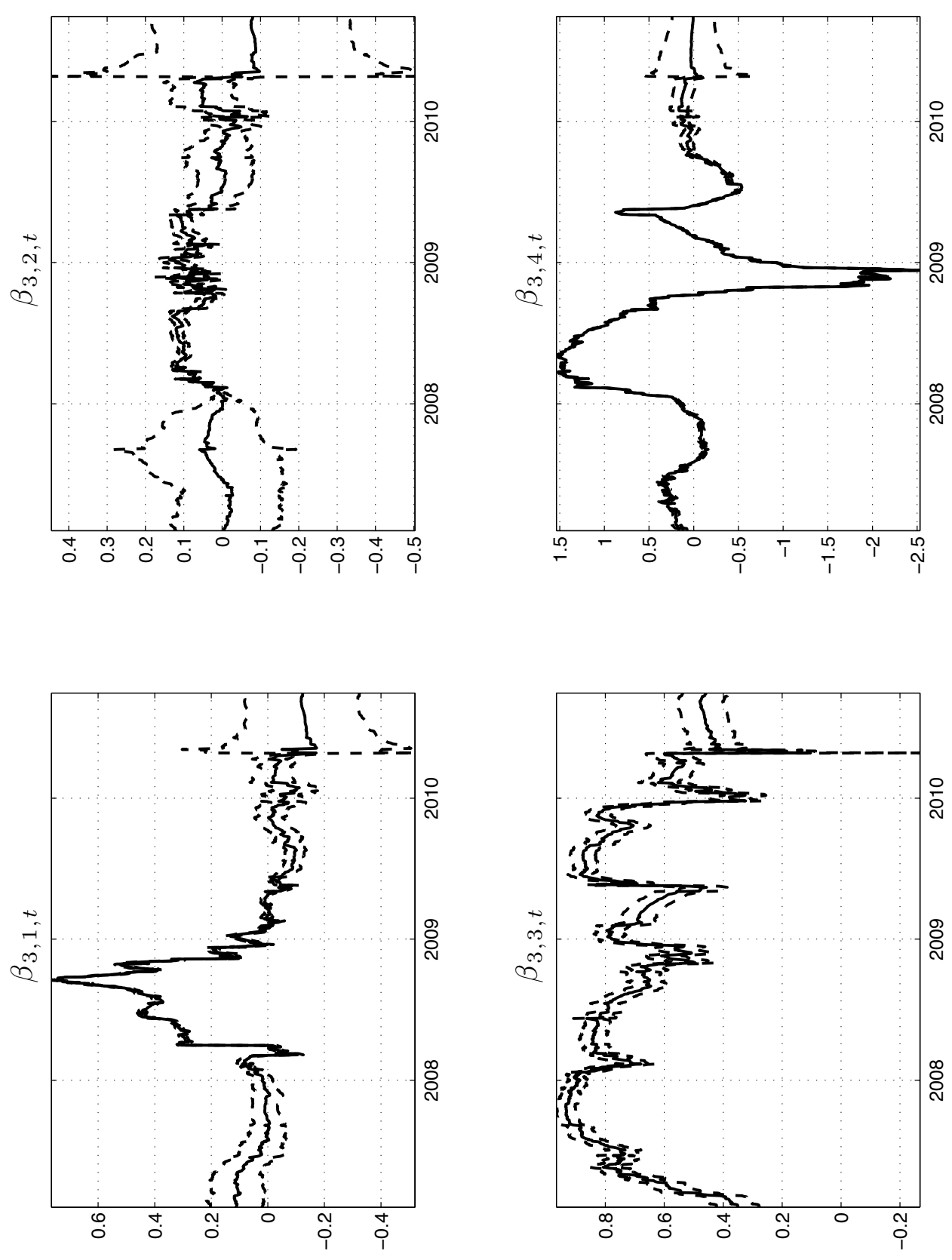

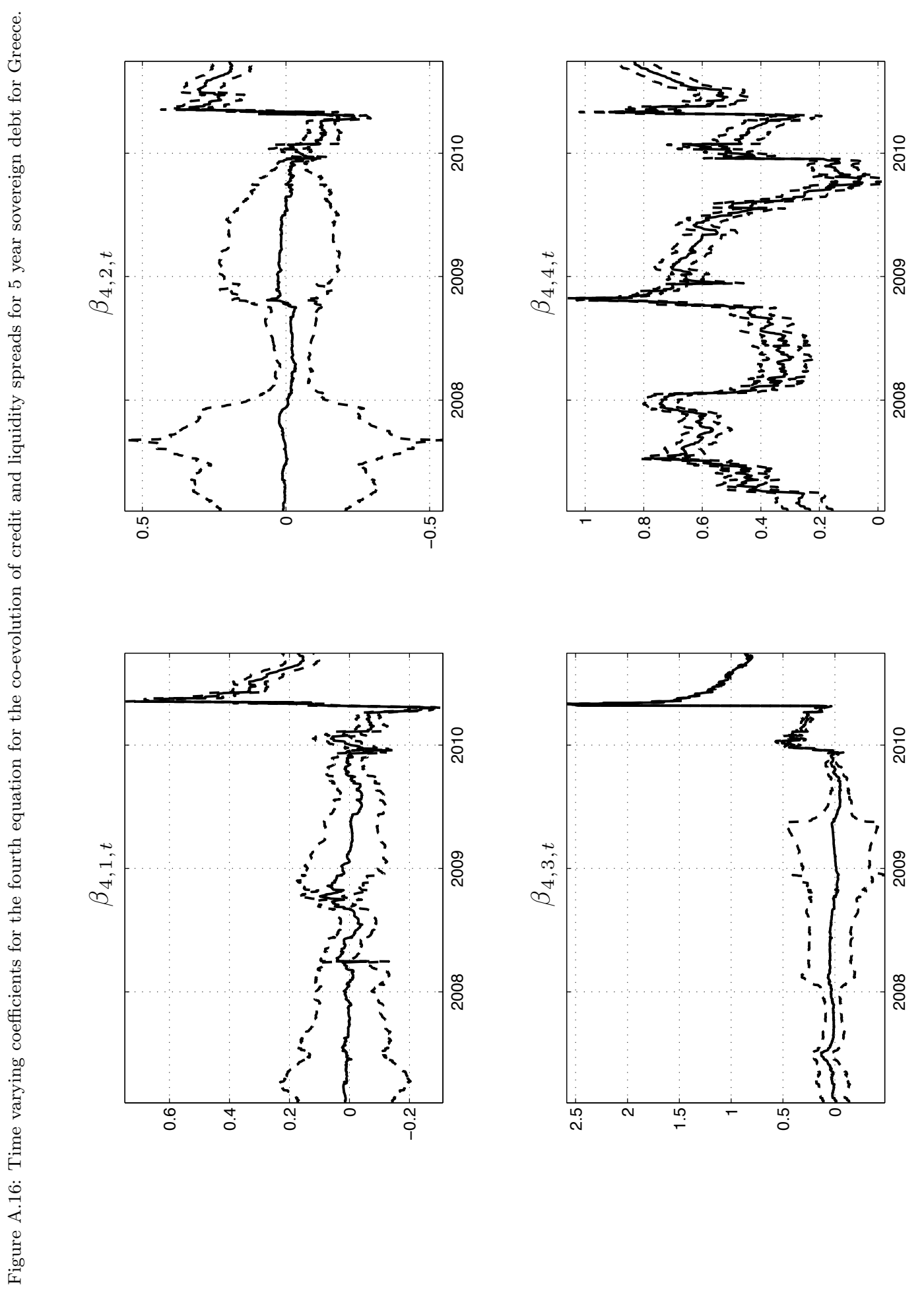

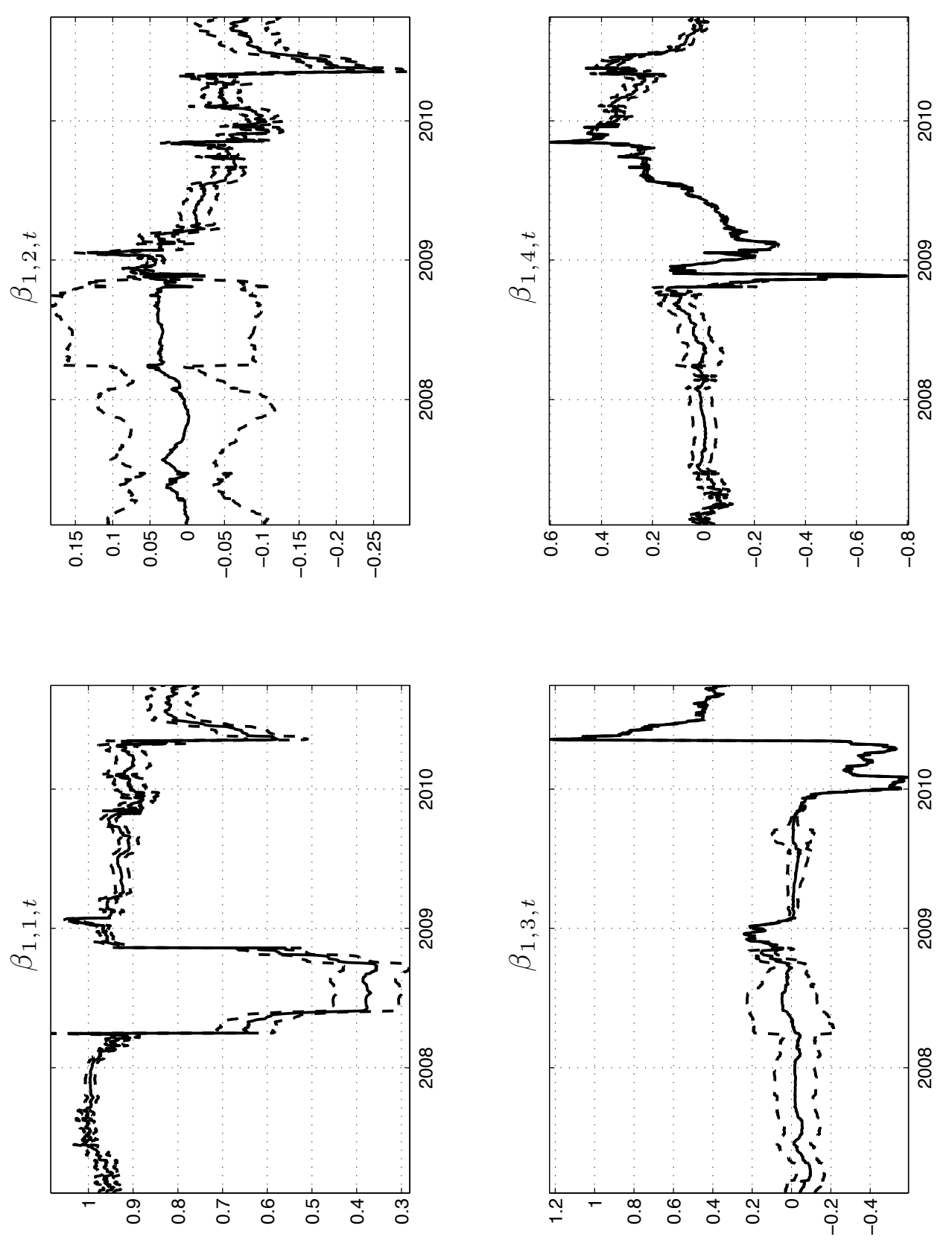

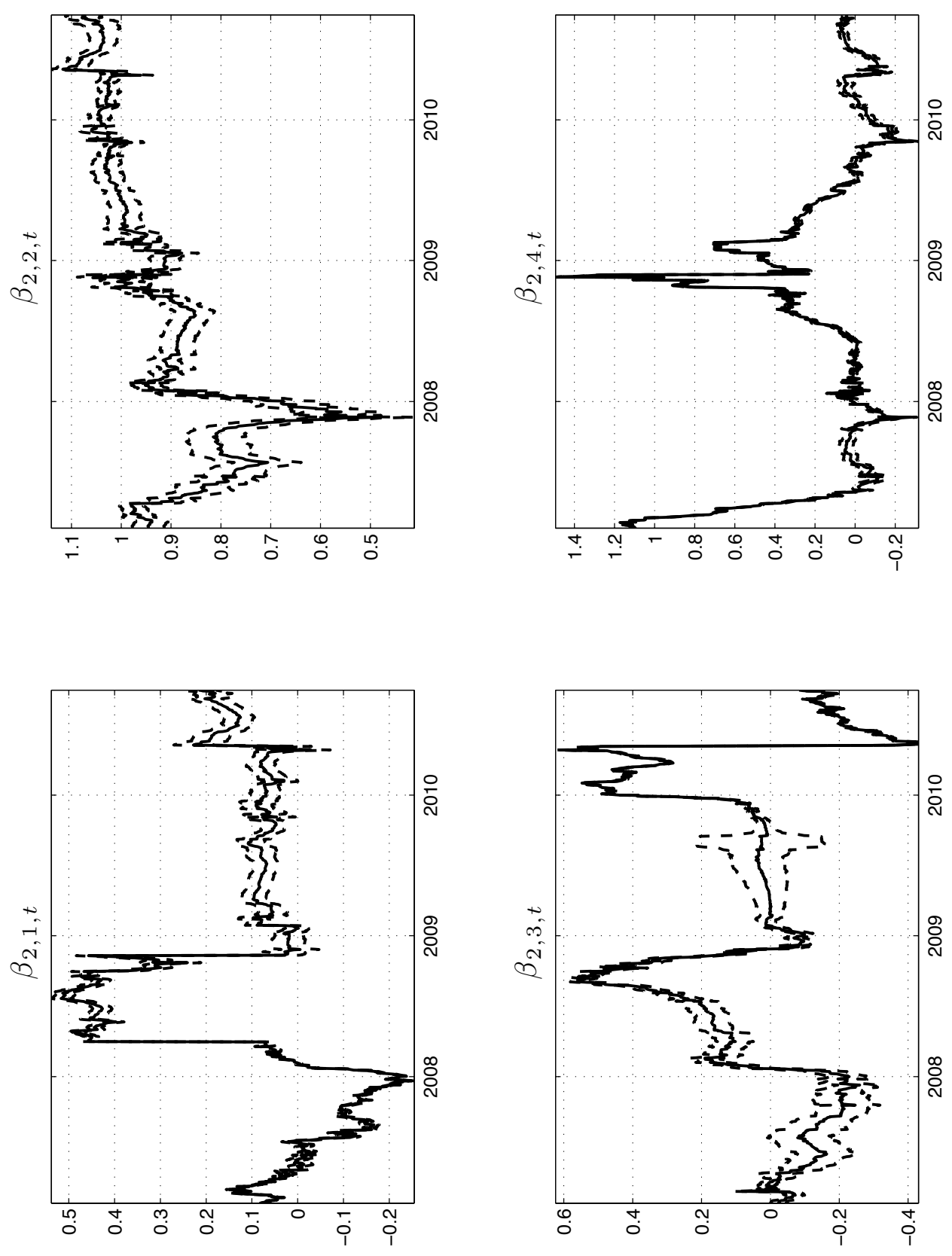

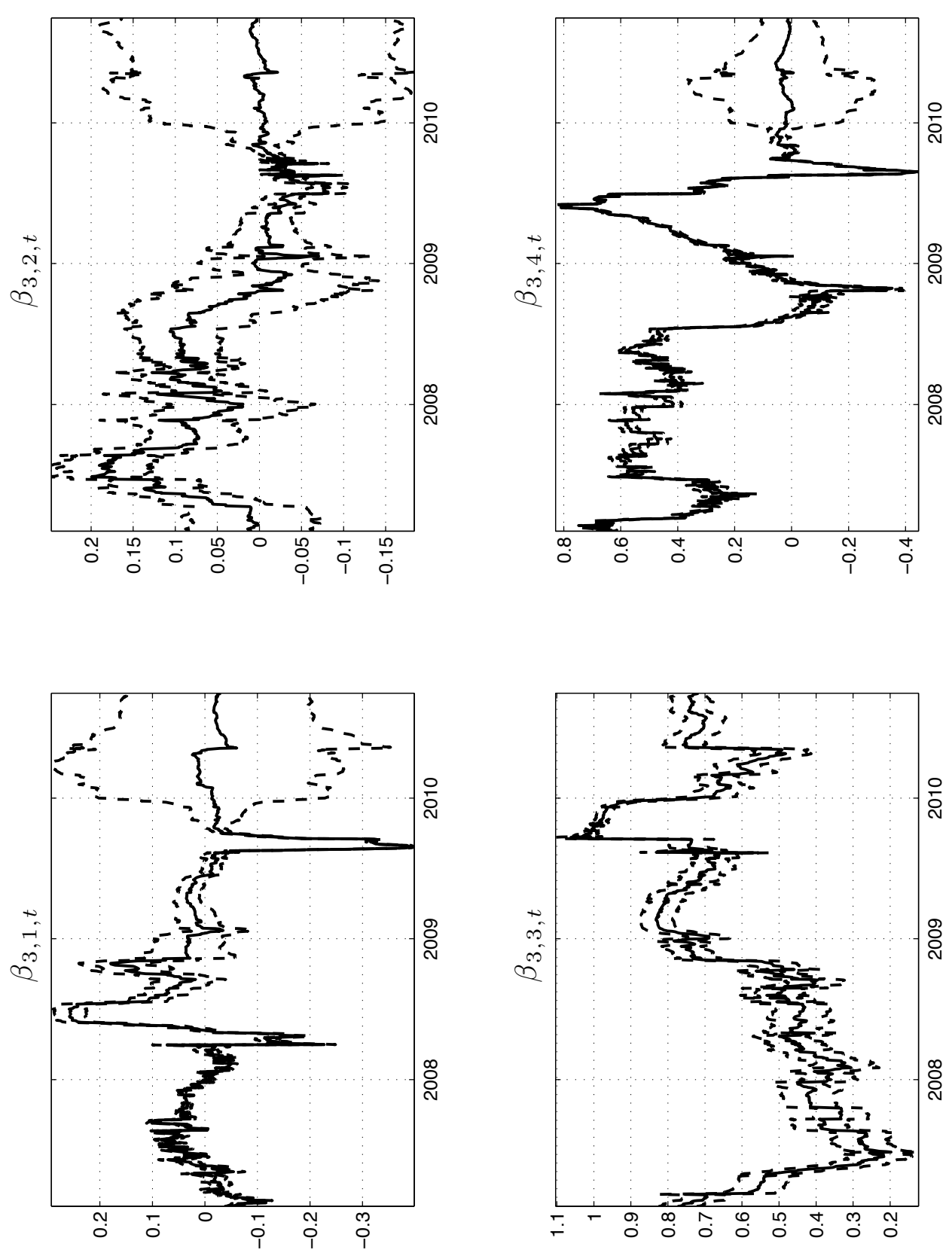

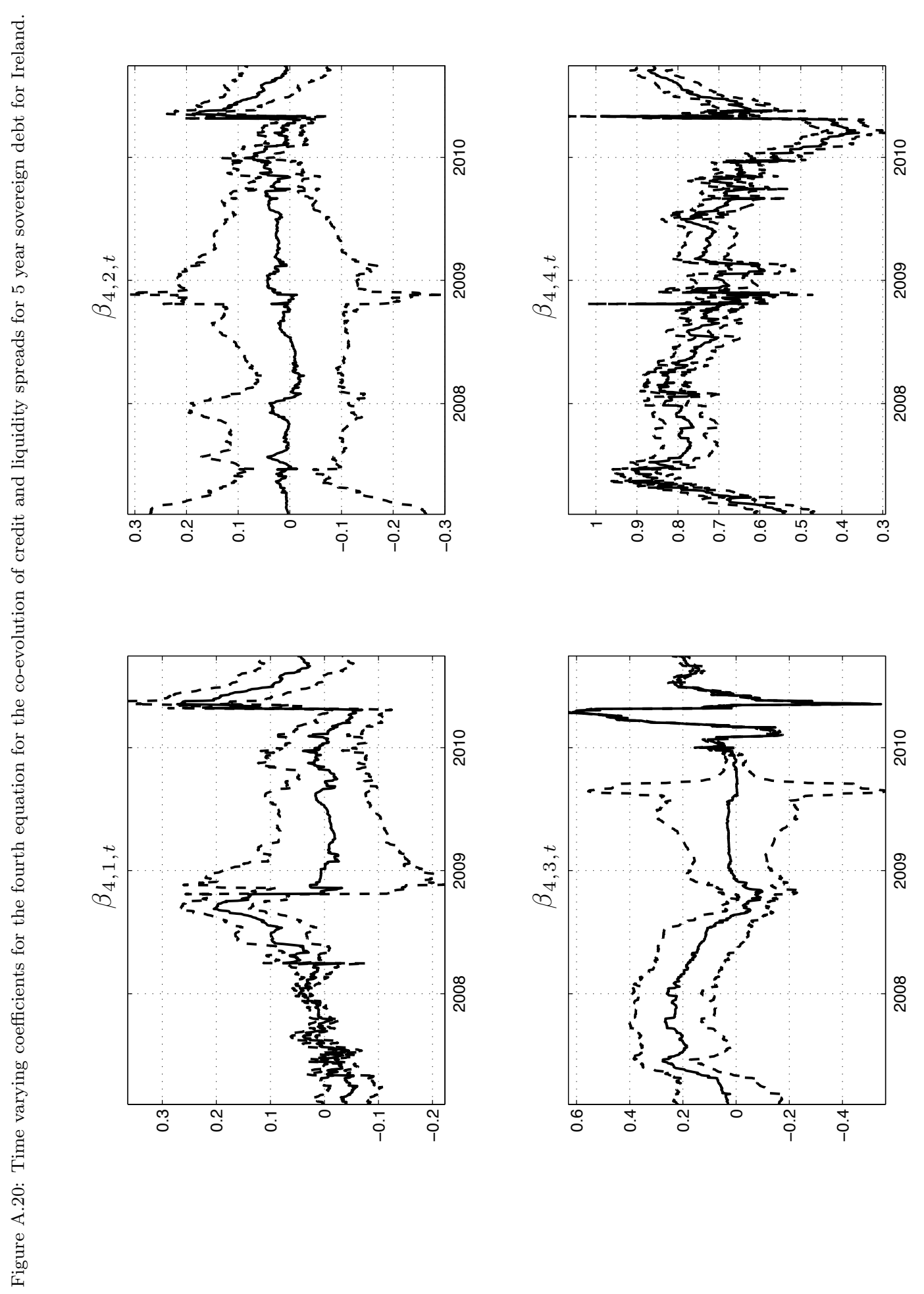

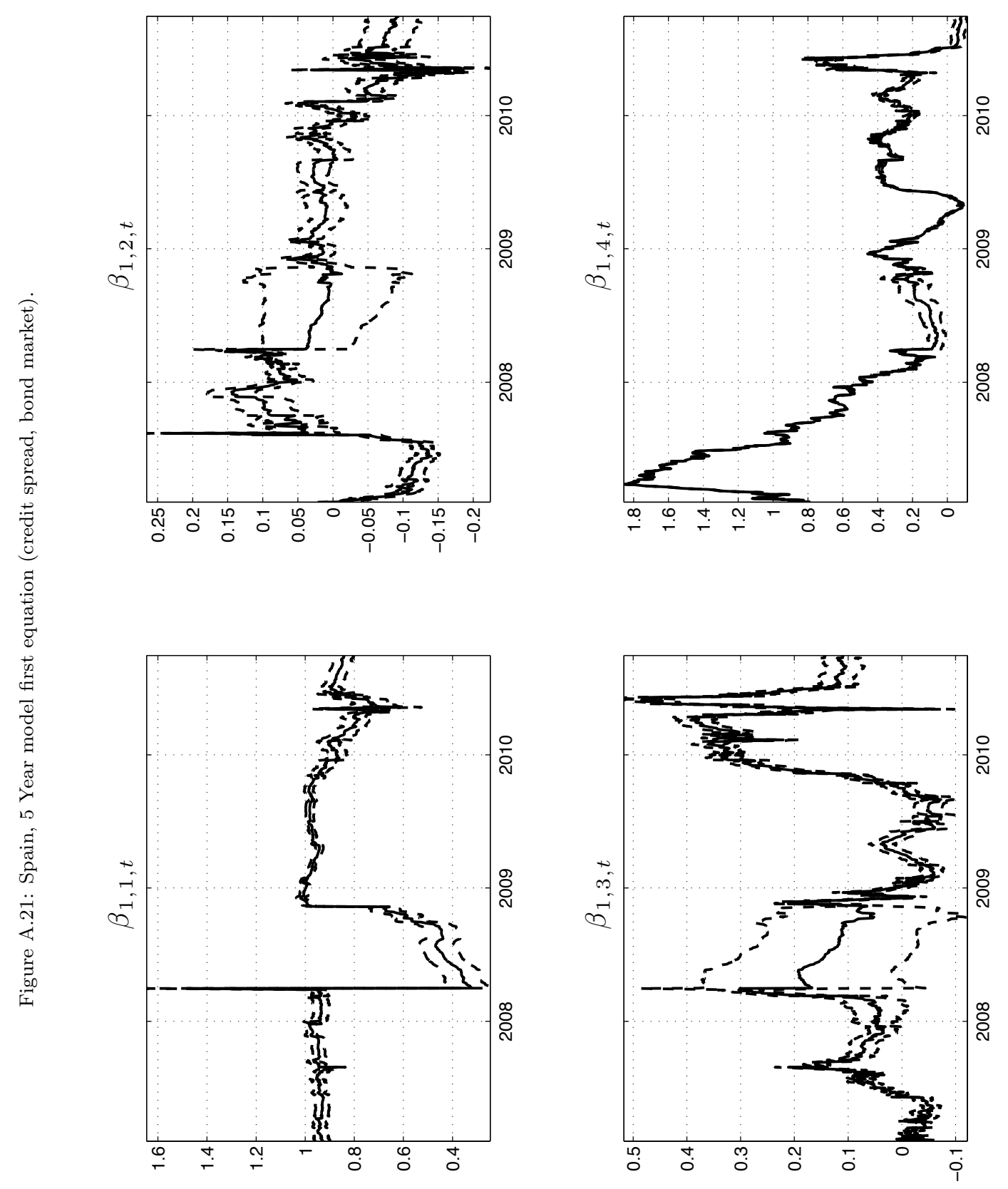

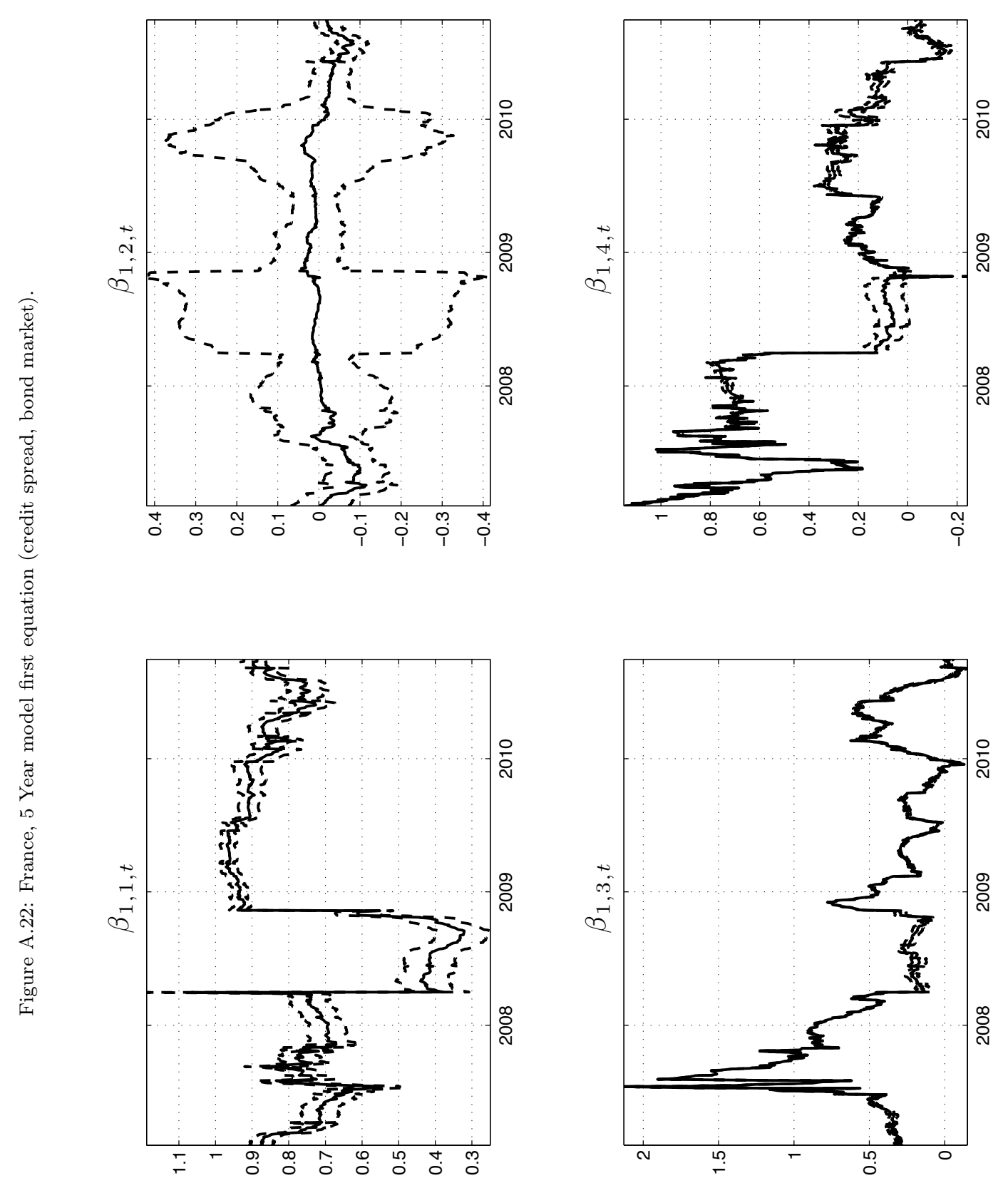

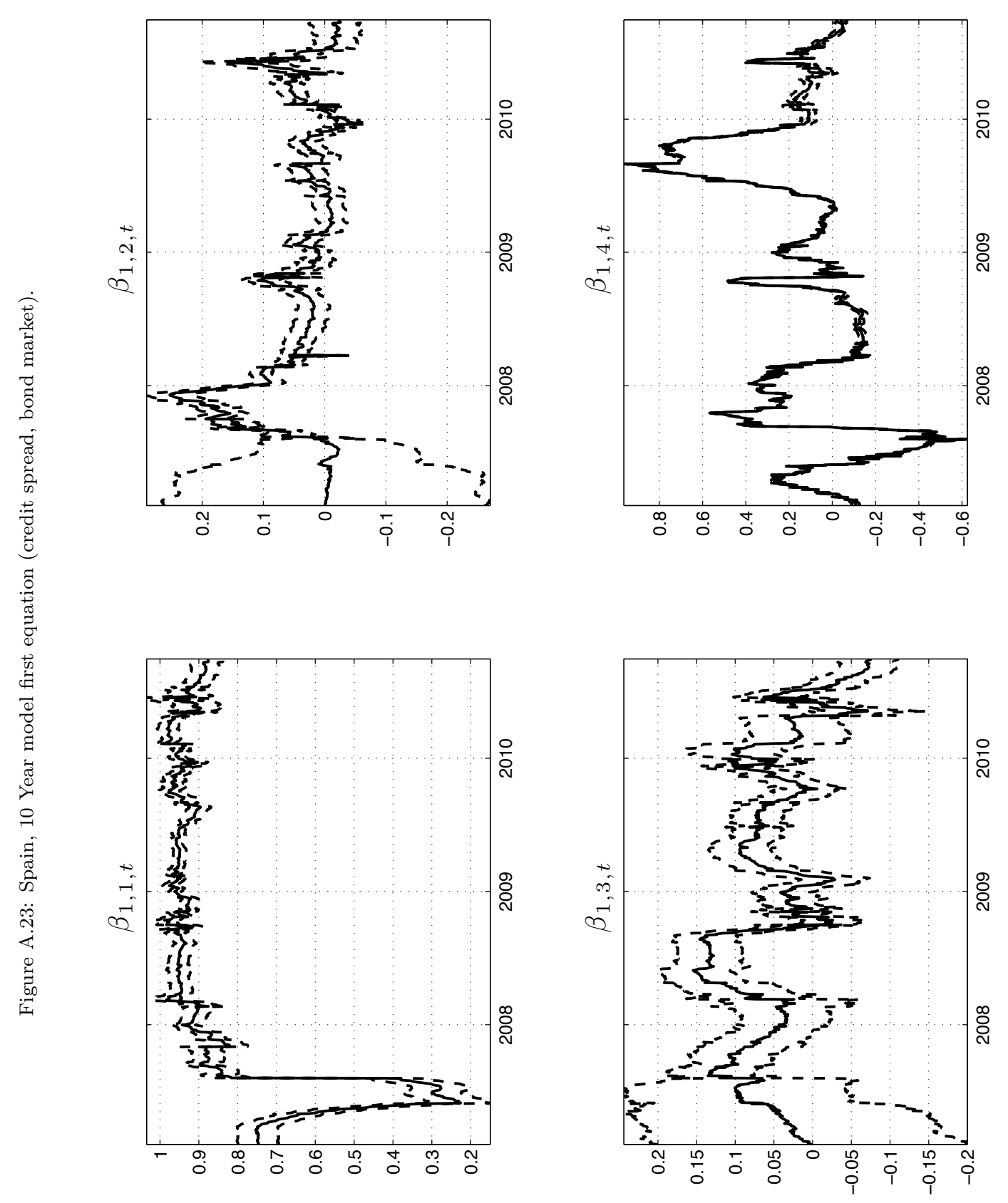

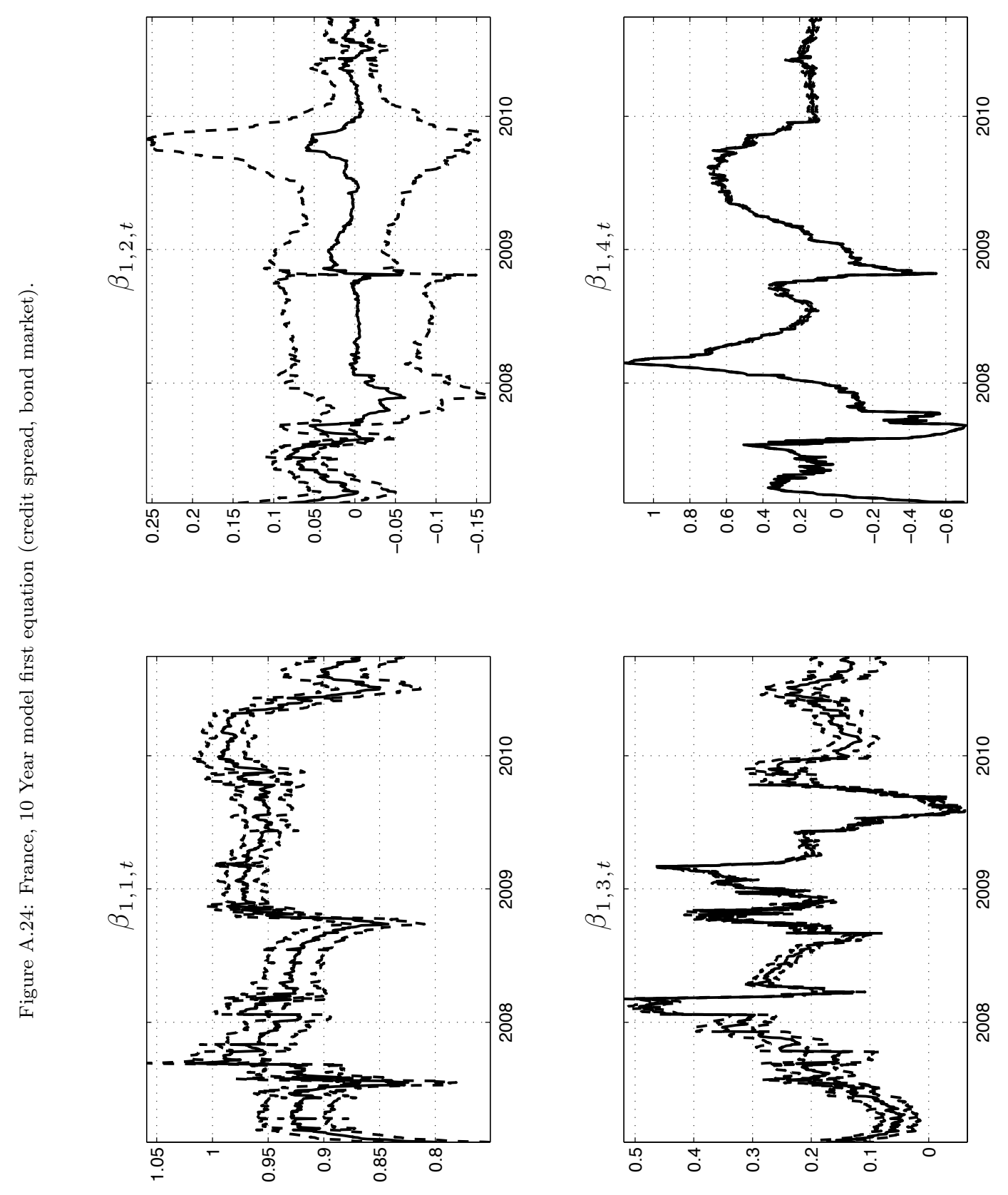